

\section{DISCLAIMER}

This report was prepared as an account of work sponsored by an agency of the United States Government. Neither the United States Government nor any agency Thereof, nor any of their employees, makes any warranty, express or implied, or assumes any legal liability or responsibility for the accuracy, completeness, or usefulness of any information, apparatus, product, or process disclosed, or represents that its use would not infringe privately owned rights. Reference herein to any specific commercial product, process, or service by trade name, trademark, manufacturer, or otherwise does not necessarily constitute or imply its endorsement, recommendation, or favoring by the United States Government or any agency thereof. The views and opinions of authors expressed herein do not necessarily state or reflect those of the United States Government or any agency thereof. 


\section{DISCLAIMER}

Portions of this document may be illegible in electronic image products. Images are produced from the best available original document. 


\section{URANIUM-233 PURIFICATION AND CONVERSION TO ST ABILIZED CERAMIC GRADE URANIA FOR LWBR FUEL FABRICATION \\ (LWBR Development Program)}

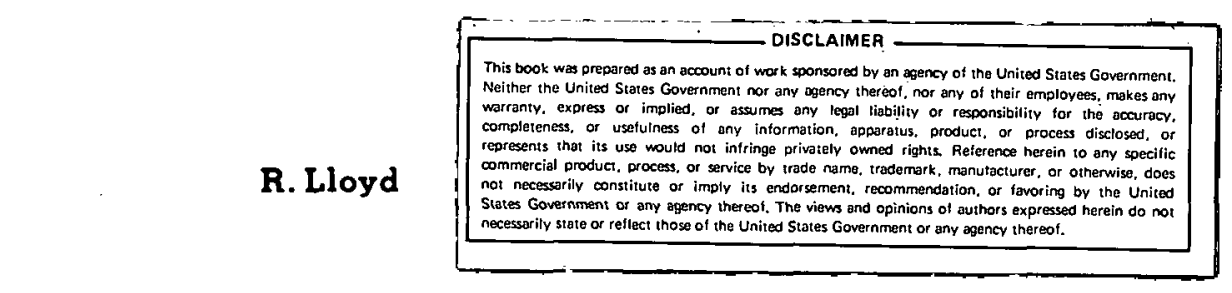

Contract No. DE-AC1 1-76PNOOO14

OCTOBER 1980

Printed in the United States of America

Available from the

National Technical Information Service

U. S. Department of Commerce

5285 Port Royal Road

Springfield, Virginia 22151

\section{NOTE}

This document is an interim memorandum prepared primarily for internal reference and does not represent a final expression of the opinion of Westinghouse. When this memorandum is distributed externally, it is with the express understanding that Westinghouse makes no representation as to completeness, accuracy, or usability of information contained therein.

\section{BETTIS ATOMIC POWER LABORATORY}

WEST MIFFLIN, PENNSYLVANIA

Operated for the U. S. Departmont of Enorgy hy

WESTINGHOUSE ELECTRIC CORPORATION 
This report was prepared as an account of work sponsored by the United States Government. Neither the United States, nor the United States Department of Energy nor any of their employees, nor any of their contractors, subcontractors, or their employees, makes any warranty, expressed or implied, or assumes any legal liability or responsibility for the accuracy, completeness or usefulness of any information, apparatus, product, or process disclosed, or represents that its use would not infringe privately owned rights. 


\section{FOREWORD}

The Shippingport Atomic Power Station located in Shippingport, Pennsylvania was the first large-scale, central-station nuclear power plant in the United States and the first plant of such size in the world operated solely to produce electric power. This program was started in 1953 to confirm the practical application of nuclear power for large-scale electric power generation. It has provided much of the technology being used for design and operation of the commercial, centralstation nuclear power plants now in use.

Subsequent to development and successful operation of the Pressurized Water Reactor in the Atomic Energy Commission (now Department of Energy, DOE) owned reactor plant at the Shippingport A tomic Power Station, the A tomic Energy Commission in 1965 undertook a research and development program to design and build a Light Water Breeder Reactor core for operation in the Shipping port Station.

The objective of the Light Water Breeder Reactor (LWBR) program has been to develop a technology that would significantly improve the utilization of the nation's nuclear fuel resources employing the well-established water reactor technology. To achieve this objective, work has been directed toward analysis, design, component tests, and fabrication of a water-cooled, thorium oxide fuel cycle breeder reactor for installation and operation at the Shippingport Station. The LWBR core started operation in the Shipping port Station in the Fall of 1977 and is expected to be operated for about 4 to 5 years or more. At the end of this period, the core will be removed and the spent fuel shipped to the Naval Reactors Expended Core Facility for a detailed examination to verify core performance including an evaluation of breeding characteristics.

In 1976, with fabrication of the Shippingport LWBR core nearing completion, the Energy Research and Development Administration, now DOE, established the Advanced Water Breeder Applications (AWBA) program to develop and disseminate technical information which would assist U.S. industry in evaluating the LWBR concept for commercial-scale applications. The program is exploring some of the problems that would be faced by industry in adapting technology confirmed in the LWBR program. Information being developed includes concepts for commercial-scale prebreeder cores which would produce uranium-233 for light water breeder cores while producing electric power, improvements for breeder cores based on the technology developed to fabricate and operate the Shippingport LWBR core, and other information and technology to aid in evaluating commercial-scale application of the LWBR concept.

All three development programs (Pressurized Water Reactor, Light Water Breeder Reactor, and Advanced Water Breeder Applications) are under the technical direction of the Office of the Deputy Assistant Secretary for Naval Reactors of DOE. They have the goal of developing practical improvements in the utilization of nuclear fuel resources for generation of electrical energy using water-cooled nuclear reactors.

Technical information developed under the Shippingport, LWBR, and AWBA programs has been and will continue to be published in technical memoranda, one of which is this present report. 
II. PRODUCTION AND RECOVERY OF URANIUM-233 FOR LWBR CORE

A. Irradiation of Thoria

B. Recovery of Uranium-233

III. REQUIREMENTS $\mathrm{OF}^{233} \mathrm{UO}_{2}$ FOR FABRICATING LWBR CORE

A. Chemical and Physical Attributes

B. Neutron Poison Equivalence

IV. ION EXCHANGE DECONTAMINATION OF URANIUM-233

A. Ion Exchange Decontamination Process Principles

B. Cation Exchange Flowsheet Laboratory Development

C. Column Operating Parameters

1. Resin Cross Linkage

2. Acidity of Feed Solution

3. Uranium Concentration in Feed Solution

4. Column Scaling

5. Column Eluent

6. Pressure Drop

D. Production Scale Ion Exchange Decontamination and Purification Process

1. Sources of Ion Exchange Process Feed

2. Uranium Recovery From Scrap

3. Ion Exchange Production Process Operations

8

E. Plant Scale Evaluation of Production Ion Exchange Process

V. CONVERSION OF URANIUM-233 TO URANIA $\left(233 \mathrm{UO}_{2}\right)$

A. Urania Conversion Flowsheet Development

1. Precipitation of ADU

2. Microwave Drying of ADU

3. Reduction of $A D U$ to $\mathrm{UO}_{2}$

4. Stabilization of $\mathrm{UO}_{2}$

B. Urania Conversion Production Process

1. Urania Conversion Production Process Evaluation

VI. URANIUM-233 PURIFICATION AND ${ }^{233} \mathrm{UO}_{2}$ CONVERSION PROCESS OUTLINE

ACKNOWLEDGMENT

REFERENCES

APPENDIX: URANIUM-232 AND ITS DAUGHTER PRODUCTS

\section{LIST OF FIGURES}

Figure

1

\section{Title}

Page

Calculated ${ }^{232} \mathrm{U}$ Daughter Activity After Removal of ${ }^{228} \mathrm{Th}$ and Varying Amounts of ${ }^{224} \mathrm{Ra}$

Flowsheet for Removing Gamma Activity from ${ }^{233} \mathrm{U}$ by Sorbing ${ }^{228} \mathrm{Th}$ and ${ }^{224} \mathrm{Ra}$ on Cation Exchange Resin 


\section{LIST OF FIGURES (Cont)}

3 Growth of ${ }^{208} \mathrm{~T} 1$ Due to Decay of ${ }^{232} \mathrm{U}$

4 Decay and Regrowth of Gamma Activity in Column Effluents from Five Ion Exchange Runs with Feed Solution of Four-Year-Old Uranium Solution

Effect of Acid Concentration on the Removal of Thorium from $\mathrm{UO}_{2}\left(\mathrm{NO}_{3}\right)_{2}$

Effect of Column Length on the Thorium Loading Capacity of a Resin Column

Pressure Drops Produced at 25C with Different Types and Sizes of Resin Under Various Flow Conditions

Comparison of Pressure Drop Data Obtained with AG-50W-X12 (200-400 mesh)

Resin at 25C, Using both Laboratory-Scale and Large Columns

Production Scale Ion Exchange Decontamination and Purification Process.

Including Preparation of Process Feed Solutions

Transient Behavior of Gamma Activity in Product Solution from Plant Scale Ion

Exchange Processing of Feed Containing Two-Year-Old Uranium-233, with

8 milligrams of Uranium-232 and One Gram of Thorium per Kilogram of

Uranium-233

Chemical Process Flowsheet: Production of ${ }^{233} \mathrm{UO}_{2}$ Powder

14 Dependence of Specific Surface Area of ${ }^{233} \mathrm{UO}_{2}$ Powder upon Hydrogen Reduction 'l'emperature under Production Line Conditions

16 Radiation as a Function of Time Since Separation for 500 a of ${ }^{233}{ }_{2} \bigcap_{3}$ Powder (Containing 6.25 ppm of ${ }^{232} \mathrm{U}$ ) from Lot Number 21

\section{LIST OF TABLES}

Specifications for Thoria Used to Produce Uranium-233 With Low Uranium-232 Content 


\section{LIST OF TABLES (Cont)}

Table

5 Effect of Uranium Concentration in Feed on Thorium Loading at Breakthrough Bio Rad AG-50W-X12 Resin, 25C

6 Effects of Precipitation Variables on $\mathrm{ADU}$ and $\mathrm{UO}_{2}$ Powder

$7 \quad$ Effects of Drying Cycle Variables on $\mathrm{ADU}$ and $\mathrm{UO}_{2}$

8 Comparison of $\mathrm{UO}_{2}$ Powders from Reducing $\mathrm{ADU}$ in $\mathrm{H}_{2}$ and in $\mathrm{Ar}-4 \% \mathrm{H}_{2}$

. 9 Effect of Furnace Reduction Cycle on Specific Surface Area of $\mathrm{UO}_{2}$

10 Summary Data Sheet for $\mathrm{UO}_{2}$ Powder Product Lot Number 23

11 Process Outline for Decontamination and Purification of Uranium-233 and for its Conversion to Urania

\section{Appendix}

A-1 Nuclear Reactions in the Formation and Decay of Uranium-232 
High purity ceramic grade urania $\left(233 \mathrm{UO}_{2}\right)$ used in manufacturing the fuel for the Light Water Breeder Reactor (LWBR) core was made from uranium.233 that was obtained by. irradiating thoria under special conditions to result in not more than 10 ppm of uranium-232 in the recovered uranium-233 product. A developmental study established the operating parameters of the conversion process for transforming the uranium-233 into urania powder with the appropriate chemical and physical attributes for use in fabricating the LWBR core fuel. This developmental study included the following:

a. Design of an ion exchange purification process for removing the gamma-emitting alpha-decay daughters of uranium-232, to reduce the gamma-radiation field of the uranium-233 during LWBR fuel manufacture b. Definition of the parameters for precipitating the uranium-233 as ammonium uranate (ADU) and for reducing the ADU with hydrogen to yield a urania conversion product of the proper particle size, surface area, and ainterability for use in manufacturing the LWBR fuel

c. Establishment of parameters and design of equipment for stabilizing the urania conversion product to prevent it from undergoing excessive oxidation on exposure to the air during LWBR fuel manulacturing operations d. Development of a procedure and a facility to reprocess the unirradiated thoria-urania fuel scrap from the LWBR core manufacturing operations to recover the uranium-233 and convert it into high purity ceramic grade urania for LWBR core fabrication.

\title{
URANIUM-233 PURIFICATION AND CONVERSION TO STABILIZED CERAMIC GRADE URANIA FOR LWBR FUEL FABRICATION (IWBR Development Program)
}

\author{
R, Lloyd
}

\section{INTRODUCTION}

The Light Water Breeder Reactor (LWBR) Program is developing the technology to breed in a light water reactor in order to use nuclear fuel significantly more efficiently in light water thermal reactors. To achieve this objective, technology is being developed by designing, fabricating, and operating a breeder reactor core in the existing pressurized water reactor plant at Shippingport. Pennsylvania, owned by the Department of Energy (DOE). The LWBR design and fabrication of the reactor core has been accomplished by the Bettis Atomic Power Laboratory under the technical direction of the Division of Naval Reactors, DOE. The operation of the LWBR core in the Shippingport Atomic Power Station is expected to confirm that breeding can be achieved in a pressurized light water reactor using a thoria $\left(\mathrm{ThO}_{2}\right)$ and thoria-urania $\left(\mathrm{ThO}_{2}-\mathrm{UO}_{2}\right)$ binary fuel system. This core represents the first large scale fabrication of a thoria base binary fuel of high density and the first use of uranium-233 fabricated into ceramic fuel in a power reactor.

The LWBR corc io of seed-blanket designi, consisting of an inner region containing 12 movable seed assemblies, each surrounded by a blanket assembly. This inner region is surrounded by an outer reflector region containing 15 reflector modules. The mechanical design and operating environment of this core are described in greater detail by Connors et al. (Reference 1 ).

This report documents the urania $\left({ }^{233} \mathrm{UO}_{2}\right)$ conversion process development underlying the production of the high purity low-gamma-activity, ceramic grade urania powder used to fabricate the fuel pellets for the LWBR core. The process development involved establishing the operating parameters to manufacture stabilized urania powder possessing the chemical and physical attributes required for fabricating the LWBR fuel pellets. Prominent among the required attributes were high chemical purity, as evidenced by low neutron poison equivalence, and appropriate particle characteristics (shape, size, and surface area) to yield ceramic sinterability and fuel pellet homogeneity.

A particular objective of this process development was to reduce the gamma-radiation field of the urania powder to a value low enough to permit its processing in glove boxes. Also it was highly desirable that the rebuildup of the gamma-radiation field (due to the radioactive decay of the gamma-emitting daughter products of the uranium-232 contaminant in the ${ }^{233} \mathrm{UO}_{2}$ powder) occur at a slow rate. This would allow all of the various processing steps in the manufacture of the binary fuel pellets, up to and including final inspec- 
tion, to be carried out in glove box enclosures. These objectives were accomplished by a wide margin by means of the processes whose development is described in this document. The achievement of these goals resulted in a simple fuel pellet manufacturing facility of reduced size and in the safe and economical use of manpower from the viewpoint of reduced exposure to radiation.

The uranium-233 used in the conversion process was made by irradiating thoria under conditions to meet the specification of low uranium-232 content. An integral part of the conversion process was the initial ion exchange cleanup of the uranium-233 to remove temporarily the gamma-emitting daughters resulting from the alpha-decay of uranium-232, present at low concentration. In the interim, before the rebuildup of the uranium-232 alpha-decay daughter products, the converted urania was used in fabricating the LWBR fuel pellets by glove box operation. Under these circumstances the urania powder, prepared from the uranium233 immediately after the gamma-emitting alpha-decay daughter products of uranium-232 had been separated by ion exchange, could be processed under conditions of alpha-confinement in glove box enclosures.

\section{PRODUCTION AND RECOVERY OF URANIUM-233 FOR LWBR CORE}

\section{A. Irradiation of Thoria}

The LWBR core irradiation corresponds to the operation of a power generating core in an ongoing thorium fuel cycle reactor. The high level of urannium-232 contaminant in the uranium-2.33 fuel recovered from the normal thorium fuel cycle requires a complex, remote-handling fuel refabricating facility to recover and process the uranium-233. Such a facility has been discussed in conceptual form hy l.iverman (Reference 2). To avold the necessity of installing an expensive, heavily gamma-shielded, remote fuel fabricating facility, the LWBR core was fabricated from uranium-233 specially produced with low uranium-232 content. As discussed by Seaborg and Katzin (Reference 3) and by Boswell et al. (Reference 4), the production of uranium-233 with low uranium-232 content by neutron capture in thorium requires a well thermalized neutron flux, to favor the $(n, y)$ capture reaction in thorium and to minimize the ${ }^{232} \mathrm{Th}(n, 2 n)^{231} \mathrm{Th}$ reaction. As shown in the discussion of uranium-232 and its daughter products in the Appendix, this $(n, 2 n)$ reaction leads to the formation of uranium-232. The technical details of maintaining a thermalized neutron flux in the irradiation of thorium are discussed by Towler (Reference 5); by Crandall, Smith, and Towler (Reference 6); by Meichle (Reference 7); and by Boswell et al. (Reference 4). The special irradiation conditions for producing uranium -233 of low uranium -232 content do not exist in the power reactors of the thorium fuel cycle.

For use in the LWBR core, $750 \mathrm{~kg}$ of uranium-233 were produced at Savannah River Plant (SRP) and the Hanford Works (HW) by in-pile thermal irradiation of dense, sintered, low ionium (thorium-230) thoria powder, prepared by the sol gel process and compacted to high bulk density into aluminum jackets. The specifications for the thoria powder, given in Table 1 , included an impurity requirement for reducing the uranium-232 content of the uranium-233 produced from the thoria. The low uranium-232 content was required in order to minimize the gamma-radiation field of the urania product used to manufacture the fuel pellets for the LWBR core. The requirement of low ionium in the thoria was imposed for the purpose of holding down the production of uranium -232 by the following series of nuclear reactions:

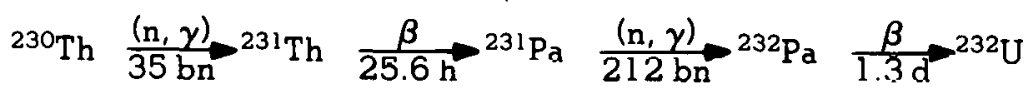

The thoria was subjected to short time (several weeks) irradiation at high thermal flux in reactors at SRP and HW fueled with enriched uranium. The short irradiation time avoided the ultimate high bulldup of uranium-232. The irradiation conditions yielded about $1 \mathrm{~kg}$ of uranium-233, containing not more than 10 ppm uranium-232, from each metric ton of thoria.

\section{B. Recovery of Uranium-233}

After its irradiation, the thoria was let stand to allow its content of $27.4 \mathrm{~d}$ protactinium-233, resulting from the irradiation, to undergo beta-decay to uranium-233. Then the irradiated thoria was dissolved and the uranium-233 was recovered by solvent extraction following the procedure of Rainey and Moore (Reference 8). The engineering process development and facility design involved in the application of this procedure are discussed by Rathvon et al. (Reference 9). 


\section{TABLE 1. SPECIFICATIONS FOR THORIA USED TO PRODUCE URANIUM-233 WITH}

LOW URANIUM-232 CONTENT

Item

Thorium content

Ionium content

$\left.{ }^{230} \mathrm{Th}:{ }^{232} \mathrm{Th}\right)$

Total impurities

Specific impurities

Uranium

Boron

$\mathrm{Li}, \mathrm{Cd}, \mathrm{Sm}, \mathrm{Gd}, \mathrm{Dy}, \mathrm{Eu}$

Chlorine

Silicon

Loss-on-Ignition

(fired at $1050 \mathrm{C}$ for 6

$\mathrm{hr})$

Dissolution

Tap density

\section{Specification}

$87.4 \%$ minimum

$1: 1 \times 10^{6}$ maximum

2000 ppm maximum

10 ppm maximum

$\mathrm{TNT}^{\star}$ content plus $3 \mathrm{ppm}$ maximum

TNT content plus 2 ppm maximum

100 ppm maximum

$300 \mathrm{ppm}$ maximum

$1000 \mathrm{ppm}$ maximum

At least $95 \%$ of thoria sample shall dissolve in 6 hr on refluxing with $12.3 \mathrm{MHNO}_{3}$ combined with $0.025 M \mathrm{HF}$ and

$0.1 \mathrm{MAl}\left(\mathrm{NO}_{3}\right)_{3}$

$7.0 \mathrm{~g} / \mathrm{cm}^{3}$ minimum

\section{Basis}

Control on total impurity levels; theoretical content, 87.9\%

Based on ability of the supplier to produce; ${ }^{230} \mathrm{Th}$, which converts to ${ }^{232} \mathrm{U}$ upon irradiation, should be held to a minimum

Control of total impurities; analysis performed for $\mathrm{Al}, \mathrm{B}$, $\mathrm{Be}, \mathrm{Bi}, \mathrm{C}, \mathrm{Cd}, \mathrm{Cl}, \mathrm{Co}, \mathrm{Cr}, \mathrm{Cu}, \mathrm{Dy}, \mathrm{Eu}, \mathrm{Fe}, \mathrm{K}, \mathrm{Li}, \mathrm{Mg}, \mathrm{Mn}$, $\mathrm{Na}, \mathrm{Ni}, \mathrm{P}, \mathrm{Pb}, \mathrm{Si}, \mathrm{Sn}, \mathrm{Sm}, \mathrm{U}, \mathrm{Zn}$

Undesirable isotopic diluent in ${ }^{233} \mathrm{U}$ product

Neutron absorber, high cross-section impurity

Neutron absorber, high cross-section impurity

Accelerates corrosion in separations equipment

Tends to form emulsions during separation by solvent extraction

Ability of supplier and requirement that material will not off-gas sufficiently to produce enough internal pressure to distort aluminum jacket

Required for economical separation of ${ }^{233} \mathrm{U}$ from thoria

To attain compacted bulk densities above $70 \%$ of theoretical in core of the target element to minimize displacement of fuel in the reactor

To attain high compacted bulk densities

$$
\begin{array}{ll}
+6 & 0 \\
-6+20 & 10 \text { to } 60 \\
-20+70 & 15 \text { to } 50 \\
-70+200 & 15 \text { to } 50 \\
-200 & 0 \text { to } 50
\end{array}
$$

Mesh

Percent

ॠThorium Nitrate Tetrahydrate. 
To recover the uranium-233, the irradiated thoria was first dejacketed by dissolving the aluminum containers either in a solution of caustic soda and sodium nitrate or in nitric acid catalyzed with mercuric nitrate. The thoria was then dissolved with a heel under reflux in boiling $12 \mathrm{M}$ nitric acid which was $0.032 \mathrm{M}$ to $0.05 \mathrm{M}$ in fluoride ion as a catalyst and $0.20 \mathrm{M}$ to $0.27 \mathrm{M}$ in aluminum nitrate, which was added to inhibit corrosion of the type 304 stainless steel dissolver. The resulting thorium nitrate solution was evaporated to $0.1 \mathrm{~N}$ acid deficiency in preparation for solvent extraction. With pulse columns at HW and mixer-settlers at SRP, the thorium and uranium -233 were co-extracted into 30 percent tributyl phosphate (TBP) in a kerosene (Ultrasene) diluent. The thorium and uranium-233 were then partitioned from the organic phase by first stripping out the thorium with $0.3 \mathrm{M}$ nitric acid and then stripping out the uranium with $0.01 \mathrm{M}$ nitric acid. The recoveries of thorium and uranium by solvent extraction exceeded 99 percent. The uranium-233 was obtained free of fission products and temporarily free of the decay products of the uranium-232 isotopic contaminant.

The thorium, in solution as thorium nitrate, was concentrated by evaporation and held in tank storage on site. The uranium-233 product, in solution as uranyl nitrate, was concentrated by evaporation (to about 250 grams of uranium per liter) at $\mathrm{HW}$ or by ion exchange and elution (to about 40 grams of uranium per liter) at SRP. The uranium-233 produced at HW was delivered in the form of the solution concentrate to the Oak Ridge National Laboratory (ORNL), where it was held in tank storage. The uranium-233 solution concentrate at SRP was treated with ammonium hydrnxide to precipitate ammonium uranate (ADU), which was calcined to a mixture of the uranium oxides $\mathrm{UO}_{3}$ and $\mathrm{U}_{3} \mathrm{O}_{8}$. The SRP uranium-233 oxide mixture was delivered to ORNL where it was stored in dry wells. As required for use, the SRP uranium-2.3.3 oxide mixture was dissolved in nitric acid, and the solution was plared in tank storage. In addition to the ureniurlin 233 prepared by HW and SRP for the LWBR core, a small quantity of uranium-233 held in the ORNL depository also was made available. The total quantity of uranium-233 available for manufacturing the LWBR core was 960 kilograms, corresponding to approximately 1100 kilograms of ${ }^{233} \mathrm{UO}_{2}$. Typical ORNL analyses of the uranium-233 inventory, showing the isotopic composition of the uranium and the impurities, are presented in Table 2.

\section{REQUIREMENTS OF ${ }^{23} \mathrm{UO}_{2}$ FOR FABRICATING LWBR CORE}

\section{A. Chemical and Physical A ttributes}

On account of its remotely operable shielded processing facility and its experience and expertise in the chemical processing of nuclear fuels, ORNL was selected to carry out, under Bettis direction, the conversion of the $\mathrm{HW}$ and SRL uranium-233 product into ${ }^{23} \mathrm{UO}_{2}$ powder for use by Bettis in fabricating the $\mathrm{ThO}_{2}$ ${ }^{23} \mathrm{UO}_{2}$ fuel for the LWBR demonstration core. For this application, the chemical and physical attributes of the ${ }^{233} \mathrm{UO}_{2}$ powder had to meet the requirements of Table 3 .

In addition to the requirements outlined in Table 3 , the ${ }^{233} \mathrm{UO}_{2}$ powder had to pass a sinterability test. In this test a sample of the powder lot was put through approved pellet manufacturing procedures, and the homogeneity and density of the pellets and their freedom from cracks and chips had to meet the applicable pellet specification for the lot to be accentahle. Further, to permit oomircmote fabricaliun ul the LWBR core, each 500-gram quantity of the ${ }^{23} \mathrm{UO}_{2}$ powder upon delivery at Bettis was acceptable only if its gammaradiation field gave a dose rate no greater than 6 mrem per hour at 1 foot. Ancillary to this requirement, the restriction was imposed that the ${ }^{233} \mathrm{UO}_{2}$ powder should be received at Bettis not later than 16 days after the uranium-232 decay products, accumulated in storage, were separated from the stored uranium-233 just prior to converting it to ${ }^{233} \mathrm{UO}_{2}$ powder. This avoided excessive rebuildup of radioactivity in the converted ${ }^{2.3 .3} \mathrm{UO}_{2}$, due to decay of its uranium-23' contaminant, before receipt of the powder by Bettis.

\section{B. Neutron Poison Equivalence}

The restriction on impurities expressed under the chemical requirements in Table 3 limited the amount of foreign material that might interfere with pellet sinterability or in pile performance. Dus to tho importance of limiting the loss of neutrons by parasitic capture, the average neutron poison equivalence NPE ${ }_{\text {avg }}$ (also called the average impurity content $\mathrm{AIC}$ ) of an order quantity consisting of several lots of ${ }^{233} \mathrm{UO}_{2}$ powder was devised as an acceptance criterion. For evaluating this parameter, each of 19 significant impurities was given a neutron poison equivalence factor NPEF, as listed in Table 4, which measured the relative parasitic neutron capture capacity, averaged over LWBR core life, of the impurity per ppm of its concentration in the ${ }^{233} \mathrm{UO}_{2}$ 
Origin of samples: uranium storage tanks

Form of material: $\mathrm{UO}_{2}\left(\mathrm{NO}_{3}\right)_{2}$

\begin{tabular}{|c|c|c|c|c|c|c|}
\hline Tank No. & U.5 & U.6 & U-7 & $U-8$ & U-9 & U-10 \\
\hline U conc., g/liter & $\begin{array}{l}234.79 \\
89576\end{array}$ & 250.45 & 254.80 & 257.98 & $\begin{array}{l}257.22 \\
95790\end{array}$ & 259.25 \\
\hline $\begin{array}{l}\text { Total U, } g \\
232 \mathrm{U}\end{array}$ & $\begin{array}{l}89,576 \\
6.7\end{array}$ & $\begin{array}{l}100,893 \\
8.5\end{array}$ & $\begin{array}{l}101,308 \\
9.2\end{array}$ & $\begin{array}{l}100,780 \\
8.6\end{array}$ & $\begin{array}{l}95,790 \\
8.8\end{array}$ & $\begin{array}{l}83,055 \\
10.4\end{array}$ \\
\hline $233 \mathrm{U}$ wt \% & 97.91 & 98.43 & 98.48 & 98.50 & 98.58 & 98.51 \\
\hline${ }^{234} \mathrm{U}$, wt $\%$ & 1.518 & 1.188 & 1.223 & 1.199 & 1.204 & 1.231 \\
\hline${ }^{235} \mathrm{U}$, wt $\%$ & 0.224 & 0.022 & 0.020 & 0.021 & 0.019 & 0.022 \\
\hline${ }^{236} \mathrm{U}$, wt $\%$ & 0.064 & $<0.001$ & $<0.0005$ & $<0.0005$ & $<0.0005$ & $<0.0005$ \\
\hline${ }^{238} \mathrm{U}$, wt $\%$ & 0.282 & 0.359 & 0.276 & 0.274 & 0.199 & 0.238 \\
\hline
\end{tabular}

\begin{tabular}{|c|c|c|c|c|c|c|}
\hline Al & 319 & 11 & 29 & 29 & 15 & 18 \\
\hline B & $<1$ & 1 & 4 & 1 & $<1$ & $<1$ \\
\hline $\mathrm{Ca}$ & 44 & 24 & 29 & 22 & 15 & 14 \\
\hline $\mathrm{Cd}$ & $<3$ & $<3$ & $<3$ & $<3$ & $<3$ & $<3$ \\
\hline Co & $<1$ & $<1$ & $<1$ & $<1$ & $<1$ & $<1$ \\
\hline $\mathrm{C}_{\mathrm{r}}$ & 30 & $<5$ & 22 & 8 & 7 & 9 \\
\hline $\mathrm{Cu}$ & $<3$ & $<3$ & 15 & $<3$ & $<3$ & $<3$ \\
\hline $\mathrm{Fe}$ & 599 & 30 & 51 & 36 & 29 & 43 \\
\hline $\mathrm{Hg}$ & $<10$ & $<10$ & $<10$ & $<10$ & $<10$ & $<10$ \\
\hline $\mathrm{K}$ & 24 & 6 & 5 & $<5$ & $\leqslant 5$ & 5 \\
\hline Mq & $<30$ & $<30$ & $<30$ & $<30$ & $<30$ & $<30$ \\
\hline $\mathrm{Mn}$ & $<1$ & $<1$ & 1 & 7 & $<1$ & $<1$ \\
\hline Mo & $<10$ & $<10$ & $<10$ & $<10$ & $<10$ & $<10$ \\
\hline $\mathrm{Na}$ & $<10$ & 15 & 10 & 87 & $<10$ & $<10$ \\
\hline $\mathrm{Ni}$ & $<5$ & $<5$ & 4 & $<5$ & $<5$ & $<5$ \\
\hline $\mathrm{P}$ & 48 & 83 & 220 & 160 & 88 & 80 \\
\hline $\mathrm{Pb}$ & $<5$ & $<5$ & $<5$ & $<5$ & $<5$ & $<5$ \\
\hline $\mathrm{Si}$ & $<50$ & $<50$ & $<50$ & $<50$ & $<50$ & $<50$ \\
\hline $\mathrm{Sn}$ & $<3$ & $<3$ & $<3$ & $<3$ & $<3$ & $<3$ \\
\hline $\mathrm{T}_{\mathrm{i}}$ & 240 & $<50$ & $<50$ & $<50$ & $<50$ & $<50$ \\
\hline Th & $<10$ & 285 & $<10$ & $<10$ & $<10$ & $<10$ \\
\hline V & -8 & $<10$. & $<10$ & $<10$ & $<10$ & $<10$ \\
\hline W & $<20$ & $<20$ & $<20$ & $<20$ & $<20$ & $<20$ \\
\hline $\mathrm{Zn}_{\mathrm{n}}$ & $<10$ & $<10$ & $<10$ & $<10$ & $<10$ & $<10$ \\
\hline${ }^{237} \mathrm{~Np}$ & $<10$ & $<10$ & $<10$ & $<10$ & $<10$ & $<10$ \\
\hline${ }^{239} \mathrm{Pu}$ & 0 & $<10$ & $<$ & $<$ & $<10$ & $<10$ \\
\hline
\end{tabular}


TABLE 3. URANIA POWDER CHEMICAL AND PHYSICAL PROPERTY ATTRIBUTES

Chemical Requirements

Attribute

Uranium concentration

Oxygen-uranium ratio

Isotopic Uranium Content

$$
\begin{aligned}
& { }^{232} \mathrm{U} \\
& { }^{233} \mathrm{U} \\
& { }^{234} \mathrm{U} \\
& { }^{235} \mathrm{U} \\
& 236 \mathrm{U} \\
& 238 \mathrm{U}
\end{aligned}
$$

$$
\text { Impurity }
$$

Al

B

C

$\mathrm{Cd}_{\mathrm{d}}$

$\mathrm{Cl}+\mathrm{Br}$

Co

$\mathrm{Cr}$

$\mathrm{Cu}$

F

$\mathrm{Fe}$

$\mathrm{Mg}$

$\mathrm{Mn}$

Mo

N

$\mathrm{Ni}$

$\mathrm{P}$

$\$ i$

Ti

$\mathrm{V}$

$\mathrm{Pu}$

$\mathrm{Hg}$

Th

Mnisture contont

\section{Property}

Partiole oise distribution: $<50$ microns

$<10$ microns

$<2.5$ microns

Average particle size

\section{Requirement}

Minimum of $86.5 \mathrm{w} / \mathrm{o}$ uranium Not to exceed 2.18

10 ppm maximum

97.0 w/ó mınımum

2.5 w/o maximum

0.5 w/o maximum

0.1 w/o maximum

1.25 w/o maximum

Maximum Individual Limit, ppm

$2 n n$

3

500

50

25

15

100

40

30

400

100

20

100

50

300

150

75

200

20

50

25

30

500

$0.6 \mathrm{w} / \mathrm{o}$ maxinílum

Physical Properties

$$
\underline{\mathrm{UO}_{2}}
$$

Minimum of $96 \%$

Minimum of $90 \%$

Minimum of 50\%

Not greater than 2 microns 
TABLE 3. URANIA POWDER CHEMICAL AND PHYSICAL PROPERTY ATTRIBUTES (Cont)

\section{Physical Properties (Cont)}

\section{Property}

Surface area

Foreign materials
$6+2 \mathrm{~m}^{2} / \mathrm{g}$

A $12 \pm 1-g$ sample upon examination shall not contain:

(1) Single foreign body with mean diameter $>0.030$ in.

(2) More than two foreign bodies with mean diameter $>0.015$ in.

(3) More than six foreign bodies with mean diameter $\leqslant 0.015$ in.

\section{TABLE 4. NEUTRON POISON EQUIVALENCE FACTORS}

Impurity

Al

B

$\mathrm{Ca}$

$\mathrm{Cl}+\mathrm{Br}$

Co

$\mathrm{Cr}$

$\mathrm{Cu}$

$\mathrm{Fe}_{\boldsymbol{\theta}}$

$\mathrm{Mg}$
Neutron Poison Equivalence Factor

0.01

30.0

0.07

1.2

1.0

0.07

0.09

0.06

0.03

\section{Impurity}

$\mathrm{Mn}$

Mo.

$\mathrm{N}$

$\mathrm{Ni}$

$P$

$\mathrm{S}$

$\mathrm{Si}$

'li

$\mathrm{V}$
Neutron Poison Equivalence Factor
0.34

0.11

0.11

0.11

0.03

0.02

0.02

0.16

0.13

1.13 
The total neutron poison equivalence TNPE of any given ${ }^{233} \mathrm{UO}_{2}$ powder lot was computed by summing the products obtained from multiplying the neutron poison equivalence factor of each listed impurity by the concentration in ppm of that impurity in the powder lot. Thus, for any powder lot PL, the total neutron poison equivalence was expressed as follows:

where

$$
\mathrm{TNPE}_{\mathrm{PL}}=\sum_{\mathrm{I}=1}^{19} \mathrm{NPEF}_{1} \times \mathrm{PPM}_{\mathrm{I}}
$$

subscript $I=$ the index number (from 1 to 19 ) of the individual impurity in the powder lot

subscript $\mathrm{PL}=$ the index number of that powder lot in the order quantity

$$
\begin{aligned}
& \text { NPEF = the neutron poison equivalence factor of the individual impurity } \\
& \text { PPM = the concentration in npm nf that impurity in the specific powden lut } \\
& \text { TNPE = the total neutron poison equivalence of the spenific powder lot. }
\end{aligned}
$$

For an order quantity TOQM of ${ }^{233} \mathrm{UO}_{2}$ powder containing a number TPL of total powder lots, each of mass PLM, the average neutron poison equivalence was the average of all the total neutron poiann erguivalencer of the lulal puwder lots in the order quantity. Thus,

where

$$
\mathrm{NPE}_{\mathrm{avg}} \equiv \mathrm{AIC}=\frac{\sum_{\mathrm{PL}=1}^{\mathrm{TPL}} \mathrm{TNPE}_{\mathrm{PL}} \times \mathrm{PLM}_{\mathrm{PL}}}{\mathrm{TOQM}}
$$

$\mathrm{TPL}=$ The number of total powder lots in the order quantity of ${ }^{233} \mathrm{UO}_{2}$ powder
$\mathrm{NPE}_{\mathrm{avg}}=$ the average neutron poison equivalence of the order quantity of powder. The average neutron poison equivalence of an order quantity of ${ }^{233} \mathrm{UO}_{2}$ powder is also called its average impurity content, being then alternatively designated by the symbol AIC.

PLM $=$ the mass of the individual powder lot

TOQM $=$ the mass of the total order quantity

In order to avoid excessive amounts of neutron poisons in the fabricated fuel, the additional specification was applied that the average neutron poison equivalence NPE avg (that is, the average impurity content $A I C$ ) of an order quantity of ${ }^{233} \mathrm{UO}_{2}$ powder should not have a value greater than $\mathrm{NPE}$ avg $\equiv \mathrm{AIC}=72$. To assure meeting this requirement, the total neutron poison equivalenre TNPE of each powder lot was held during production to a value not greater than TNPE $=72$.

\section{ION EXCHANGE DECONTAMINATION OF URANIUM-233}

\section{A. Ion Exchange Decontamination Process Principles}

During the several years' storage of the HW and SRP uranium-233 product, there was a continual buildup of the decay products of its uranium-232 isotopic contaminant. The intensity of the gamma-radiation field associated with the decay products was excessive for carrying out Bettis operations with the uranium-233 in glove box enclosures. Conversion of the uranium-233 into ${ }^{233} \mathrm{UO}_{2}$ that could be handled at Bettis semiremotely with a minimum amount of gamma-shielding during LWBR core fabrication required prior removal of the uranium-232 decay products. To avoid the more expensive process of solvent extraction, ORNL freed the uranium-233 of its uranium-232 decay products by subjecting it to cation exchange in the form of the uranyl nitrate solution, following the procedure of Rainey (Reference 10). 
The ion exchange decontamination of the uranyl nitrate solution is based upon the fact that 1.9 y thorium228 and $3.64 \mathrm{~d}$ radium-224, the first and second decay products, respectively, of uranium-232, (See Table A-1 of the Appendix) have much longer half-lives than the subsequent unstable members of the uranium-232 decay chain. It also depends upon the favorable distribution coefficients of thorium, radium, and lead in solution as the nitrates, with respect to 12 percent cross-linked polystyrene sulfonic acid cation exchange resin (200 to 400 mesh Bio Rad AG-50W-X12) compared to the distribution coefficient of uranium. The relative value of these distribution coefficients in the nitrate system is such that tho:jum, radium, and, to a less extent, lead dislodge uranium from the resin saturated with uranyl ion and become preferentially attached to the ion exchange sites of the resin.

Figure 1 shows the calculated time dependence of uranium-232 gamma-activity following removal of all its thorium-228 and varying amounts of its radium-224 decay products. The subsequent short half-life daughters decay out rapidly, while the continual decay of the uranium-232 causes the daughter products to rebuild. As a result, the gamma-activity passes through a minimum value, from which it slowly builds up to the equilibrium or steady state value. If all of the thorium-228 and radium-224, but none of the remaining daughters, is removed, the gamma-activity passes through a minimum value in about five days which is approximately 0.25 percent of its equilibrium value If, in addition to all of the thorium-228 and radium224, much of the lead-212 and of the remaining decay products is also removed, the minimum value of the gamma-activity is even lower and is reached in a shorter time.

\section{B. Cation Exchange Flowsheet Laboratory Development}

The cation exchange decontamination of the uranium-233 product was studied experimentally on a laboratory scale with the flow sheet shown in Figure 2. The resin was divided into two columns, the combined volume of which was taken as a column volume. During the ion exchange decontamination, the feed solution passed through the two columns in series under a high differential pressure, flowing upward in the first column and downward in the second. At the end of the run, the uranium solution in the two columns was displaced with a water wash into the product stream. The water did not elute the uranium-232 decay products from the resin. In order to elute the decay products from the resin at the end of a run, the columns were backwashed with $6 \mathrm{M}$ nitric acid. The nitric acid was not the most effective eluent, especially for removing thorium from the resin. The nitric acid, however, introduced no foreign ions and was compatible with the process. The eluent flow through the first column was countercurrent to the product solution flow. This had the advantage that the thorium, which was not completely eluted, was pushed back to the inlet of the first column, reducing the possibility of its breaking through into the product stream. The eluate was recycled to solvent extraction for recovery of the eluted uranium-233 free of the uranium-232 decay products.

To evaluate the flowsheet of Figure 2, five laboratory ion exchange runs were carried out at $25 \mathrm{C}$ with a solution throughput of $5.3 \mathrm{grams}$ of uranium per milliliter of the resin, using resin volumes of five milliliters or less. The runs were made with aliquots of a solution of four-year-old uranium-233, which contained 100 grams per liter of uranium-233 as uranyl nitrate and up to 0.1 gram per liter of thorium and was $0.1 \mathrm{M}$ to $0.4 \mathrm{M}$ in nitric acid. Due to the small particle size of the 200 to 400 mesh Bio Rad AG-50W-X12 resin beads, a high pressure difference was required to force the solution through the columns. From the calculated data plotted in Figure 3, which shows the regrowth of thallium-208 activity in decontaminated uranium-232, the gamma-activity in the feed solution made from the four-year-old uranium-233 stock had rebuilt to about 80 percent of its equilihrium value.

At the start of a run the resin was quickly saturated with the uranium, which broke through as a decontaminated product effluent. More than 99 percent of the thorium and more than 98 percent of the radium, but only about 50 percent of the lead, were retained on the resin. Following passage of the uranyl nitrate solution, the columns were water-washed to displace into the product stream the uranium solution holdup in the columns. Then subsequent elution of the resin with $6 \mathrm{M}$ nitric acid at $25 \mathrm{C}$ removed the attached uranium and lead and approximately 90 percent of the radium, but less than half the thorium. Later studies showed that eluting with the $6 \mathrm{M}$ nitric acid at $60 \mathrm{C}$ increased significantly the fraction of thorium eluted. Temperatures higher than $60 \mathrm{C}$ caused excessive degradation of the resin.

The transient behavior of the gamma-activity in the uranium product effluents is described by the cxperimental data plot in Figure 4. Once the long-lived decay products of uranium-232 had been removed by the resin, the gamma-activity of each of the uranium-233 solution effluents decayed over a period of three days with the half-life of the incompletely removed $10.6 \mathrm{~h}$ lead-212, until the residual gamma-activity was about 0.3 percent of the equilibrium value in the feed solution. Thereafter the gamma-activity increased at 


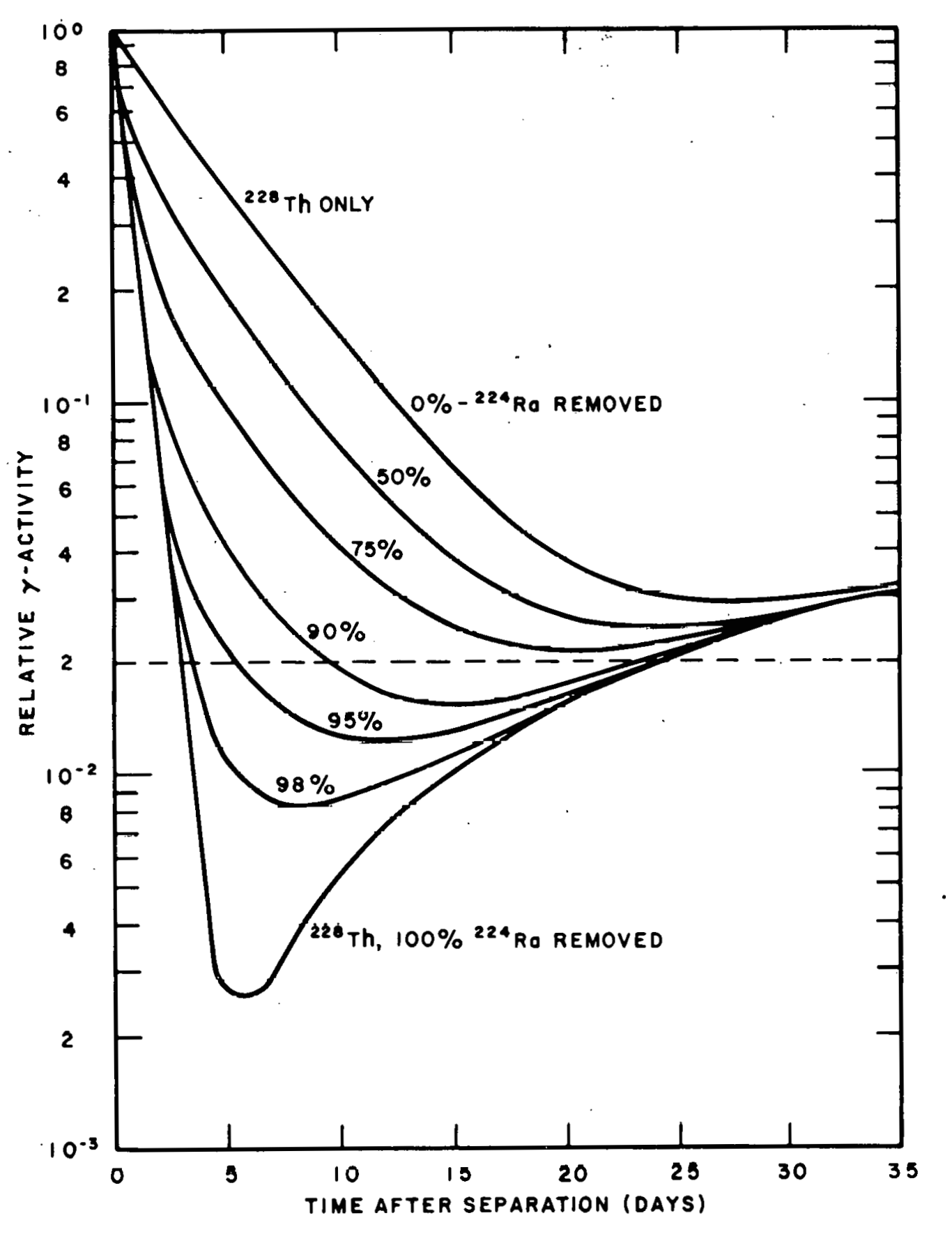

Figure 1. Calculated ${ }^{232}$ U Daughter Activity After Removal of ${ }^{228} \mathrm{Th}$ and Varying Amounts of ${ }^{224} \mathrm{Ra}$. 


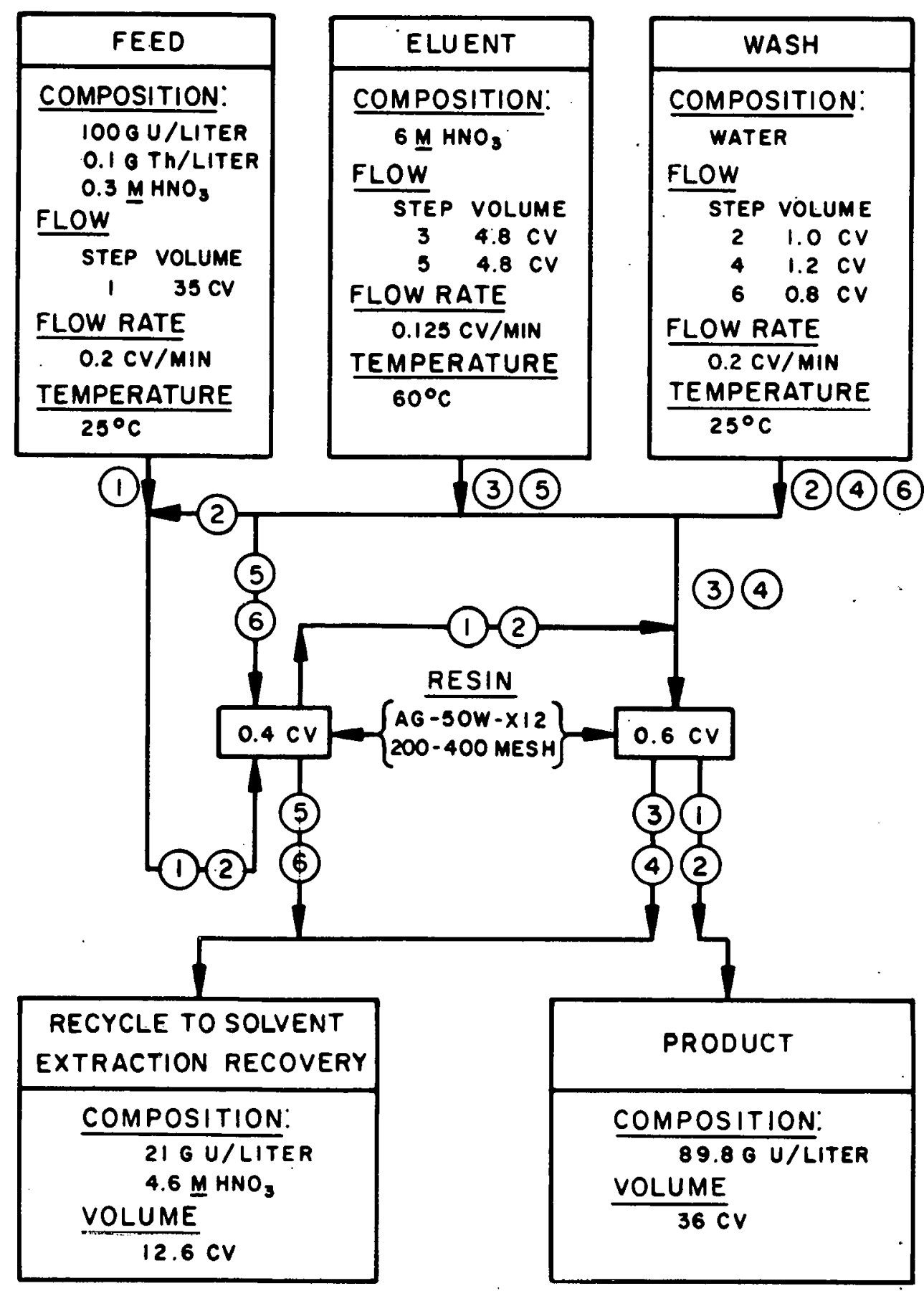

Figure 2. Flow sheet for Removing Gamma Activity from ${ }^{233} U$ by Sorbing ${ }^{228} T h$ and ${ }^{224}$ Ra on Cation Exchange Resin. (The circled numbers denote the sequence of process steps. CV denotes column volume.) 


$$
\text { D }
$$




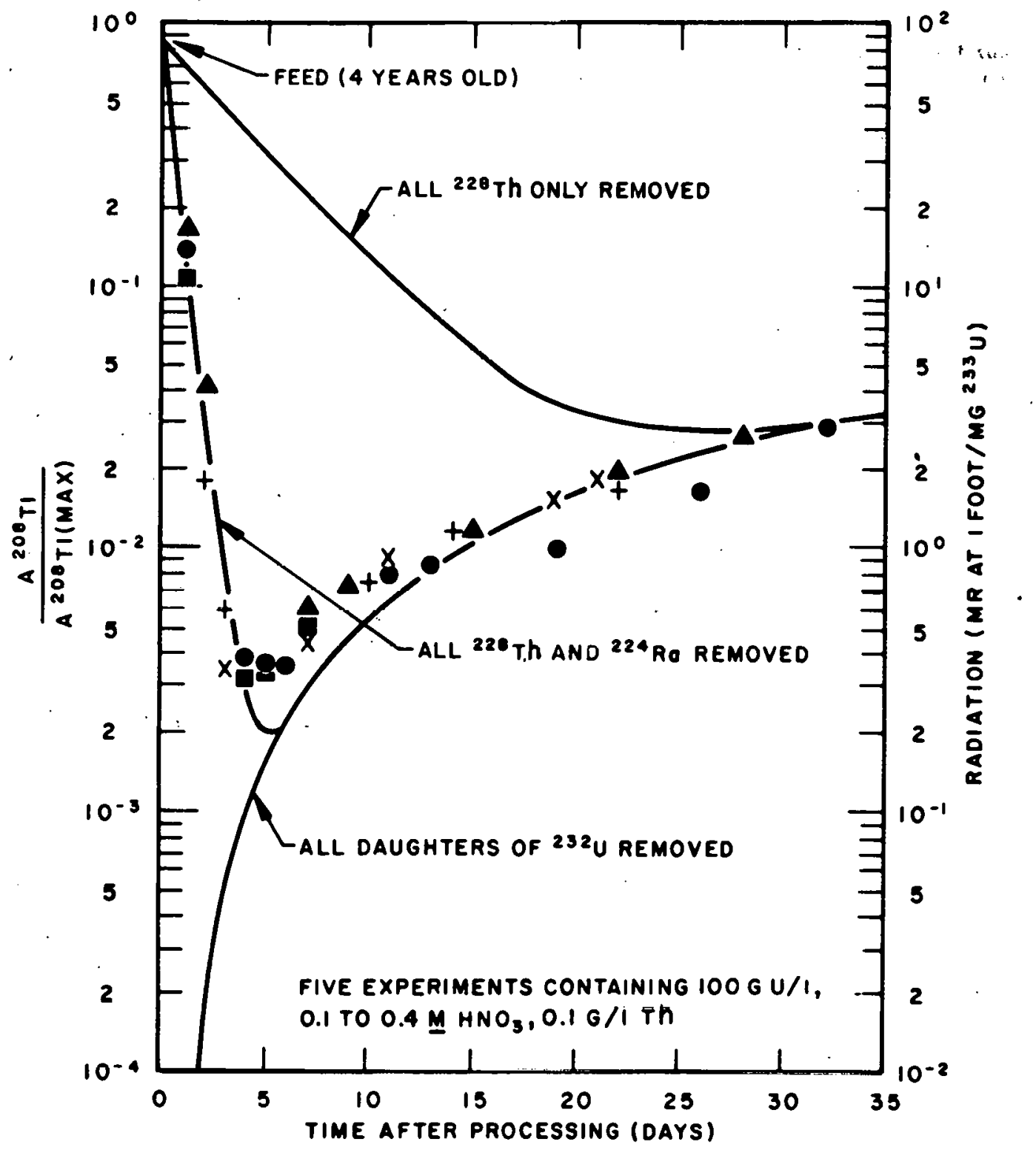

Figure 4. Decay and Regrow th of Gamma Activity in Column Effluents from Five Ion Exchange Runs with Feed Solution of Four-Year-Old Uxanium Solution. (Points give experimental data; lines show calculated theoretical values.) 
approximately the rate of regrowth of thorium-228. Between the second and the twenty-fourth day following the ion exchange cleanup, the gamma activity of each of the uranium-233 solution effluents was less than 2 percent of the equilibrium value.

\section{Column Operating Parameters}

An experimental study was made of the ion exchange column operating parameters to obtain data for a scale-up from the laboratory size columns of 5 milliliters or less to the production size columns of 6 liters.

1. Resin Cross Linkage. The Bio Rad AG-50W ion exchange resin is manufactured in both the 8 percent and 12 percent cross-linked forms. Each of these resin types was evaluated with uranium-233 solutions under identical experimental conditions in accordance with the flowsheet of Figure 2 . The effluent product from each ion exchange run was allowed to age for 72 hours for the short half-life uranium-232 decay products to decay out. The smaller the amount of high energy gamma-activity, mainly from thallium-208, in the aged solution, the more effective had been the resin in removing the long-lived thorium-228, radium224, and lead-212 decay products of uranium-232. In tests with the 8 percent cross-linked resin, the thallium-208 decontamination factor (the ratio of the thallium-208 gamma-activity in the feed solution to its activity in the column effluent after aging for 72 hours) was less than 10 . With the 12 percent cross-linked resin the decontamination factor was approximately 300. The 12 percent cross-linked resin was thus far more effective in removing the uranium-232 decay products from the feed solution than the 8 percent crosslinked resin.

2. Acidity of Feed Solution. Increasing the concentration of nitric acid in the uranium-233 feed sulution decreases the distribution coetticient of thorium with respect to the resin. The sensitivity of the thorium distribution coefficient to nitric acid concentration was evaluated with uranium-233 feed solutions that contained 112 grams of uranium and 0.67 grams of thorium per liter and varying concentrations of nitric acid. Using the Bio Rad AG-50W-Xl 2 resin, with a theoretical capacity of 0.13 grams of thorium per milliliter of wet resin, experimental runs were made which established the relationship between the acidity of the feed solution and the thorium loading on the resin at thorium breakthrough. The results of these test runs, plotted in Figure 5, show that decreasing the nitric acid concentration in the uranium-233 feed from $0.7 \mathrm{M}$ to $0.1 \mathrm{M}$ almost tripled the volume of the feed solution that could be processed through the ion exchange column before thorium breakthrough occurred.

3. Uranium Concentration in Feed Solution. In cation exchange decontamination of the uranium-233 solution, the uranyl ion quickly saturates the resin, which has a capacity of 0.27 grams of uranium per milliliter of wet resin. Clean-up of the solution, therefore, requires that the uranium-232 decay products dislodge and replace the uranyl ions already held on the ion exchange sites of the resin. Increasing the concentration of uranium in the feed solution causes the uranyl ion to be held more firmly on the resin sites. The more tirmly the uranium is held on the resin sites, the smaller is the loading on the resin of the thorium, radium, and lead (decay products of uranium-232) before they break through into the product stream. Using the Bio Rad AG-50W-X12 resin, three uranium-233 feed compositions, covering a wide range of uranium concentration, were evaluated to determine the extent to which increasing the uranium concentration in the feed decreases the thorium loading on the resin at breakthrough. The data of this study are given in Table 5 .

\section{TABLE 5. EFFECT OF URANIUM CONCENTRATION IN FEED ON THORIUM LOADING AT BREAKTHROUGH Bio Rad AG.5OW.X12 Resin, 25C}

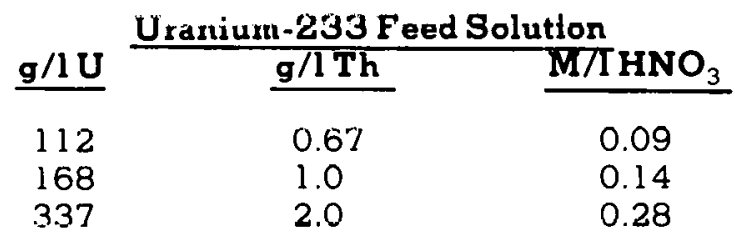

\begin{tabular}{cc}
\multicolumn{2}{c}{ Thorium Breakthrough Conditions } \\
\hline $\begin{array}{c}\text { Thorium Loading } \\
\text { \% Theoretical }\end{array}$ & $\begin{array}{c}\text { Gm UProcessed } \\
\text { per Ml Wet Resin }\end{array}$ \\
\cline { 2 - 2 } 30 & 6 \\
10 & 2.3 \\
U and Th break through together
\end{tabular}




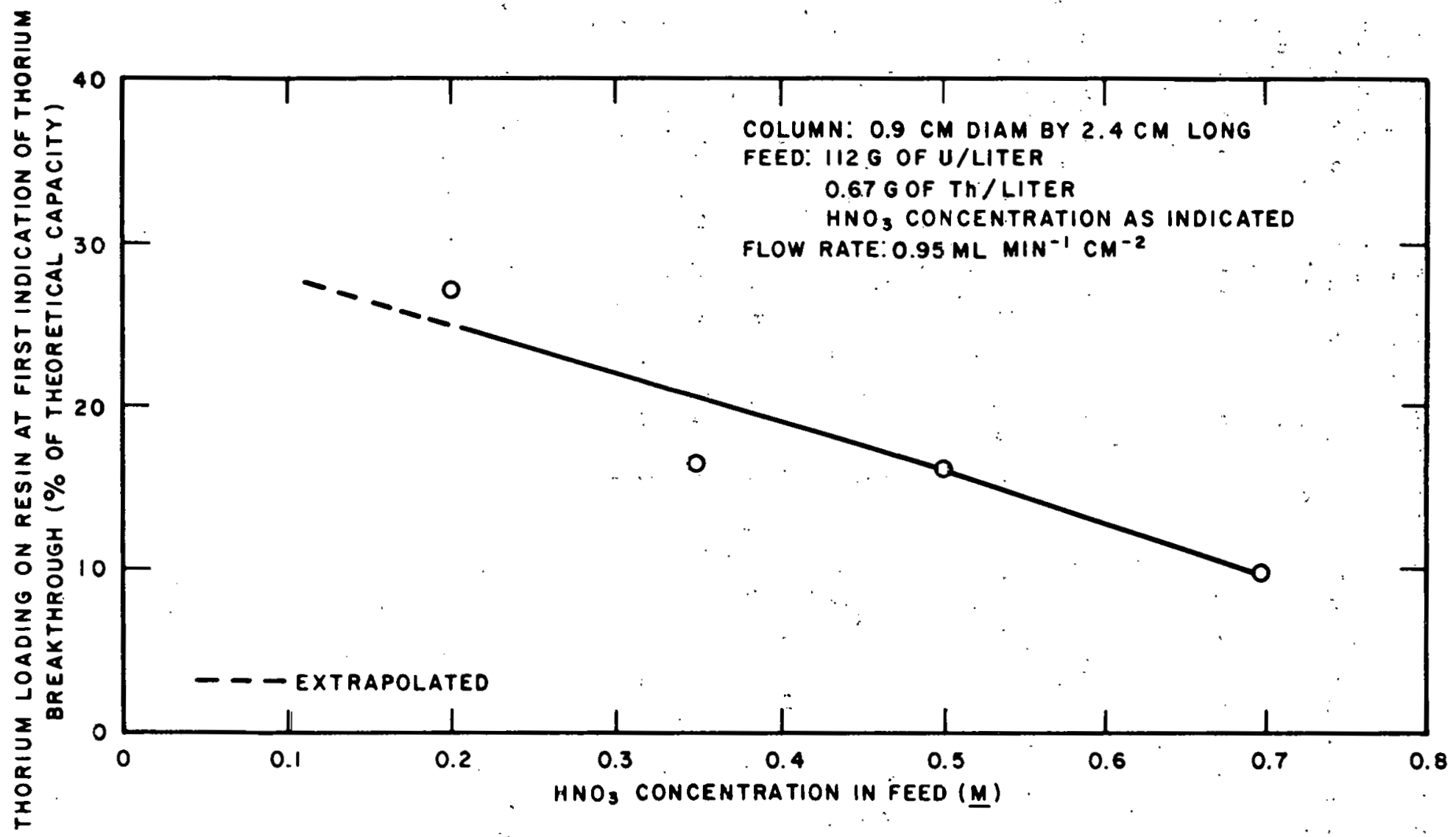


Based on the data of Table 5 and on the production schedule requirements, a uranium concentration of $120 \pm 10$ grams per liter was established for the feed in the production ion exchange process.

4. Column Scaling. A series of column scaling runs was made with a uranium-233 feed solution which contained 112 grams of uranium and 0.67 grams of thorium per liter and was $0.09 \mathrm{M}$ in nitric acid. This solution was passed through ion exchange columns of a common diameter, ranging in length from $3.4 \mathrm{~cm}$ to $27 \mathrm{~cm}$, packed with Bio Rad AG-50W-X12 resin. In each test run, the flow was adjusted so that the retention parameter (the time for one column volume of liquid to traverse the column) was held at 3.5 minutes per column volume (where a column volume is the overall volume, including void space, that is occupied by the resin). Assuming a void fraction of approximately 0.4 for a column packed with spherical resin beads, the feed solution had a residence time of 1.4 minutes in contact with the ion exchange resin in the column during each run.

In the runs a determination was made of the volume of the feed solution that had passed through the column by the time thorium breakthrough occurred. The data of these runs, plotted in Figure 6, show that the volume of the feed solution processed through the column up to the time of thorium breakthrough was linearly proportional to the column length or (because the columns had a common diameter) to the column volume. In all the runs thorium breakthrough occurred at a constant thorium loading equal to 30 percent of the theoretical. Based upon this result, the volume of the production cation exchange column was established by a linear scale-up of the laboratory columns, to permit the thorium in a volume of feed yielding 20 kilograms of uranium (the production run size) to be retained on the resin charge.

5. Column Eluent. A study was made of several eluents for regenerating the resin between runs. Regeneration was carried out subsequent to displacing the uranyl nitrate solution from the ion exchange column void space into the product stream by a water wash. Tests showed that uranium could be readily eluted from the Bio Rad AG-50W-X12 resin with $1.5 \mathrm{M}$ nitric acid at 25C. This eluent also removed lead and some of the radium. Thorium, however, could not be eluted at nitric acid concentrations below $5 \mathrm{M}$. At nitric acid concentrations of $9 \mathrm{M}$ or higher, the resin was rapidly degraded due to oxidation. Based on the laboratory test results, $6 \mathrm{M}$ nitric acid at $60 \mathrm{C}$, used at a retention parameter of 4 minutes per column volume ( 1.6 minutes residence time), was selected as the eluent for production operations. The $6 \mathrm{M}$ nitric acid at $60 \mathrm{C}$ eluted from the resin all of the attached uranium, lead, and radium and approximately 50 percent of the thorium. Eluents more effective than $6 \mathrm{M}$ nitric acid were evaluated in the study. One of the most effective eluents for removing thorium was a solution approximately $4 \mathrm{M}$ in ammonium acetate and in acetic acid. Tests showed that the uranium could be recovered by TBP solvent extraction from the eluate high in acetate ion. However, potential incompatibilities in the production operations ruled out the practical application of the acetate eluent.

6. Pressure Drop. The pressure drop characteristics of potentially applicable ion exchange resins were studied. With the several different types and sizes of resins, the pressure drop was determined in columns of various lengths and diameters over a wide range of volume flow rates. The experimental results were correlated by the relationship

$$
\Delta \mu=k \frac{V L}{A}
$$

where

$$
\begin{aligned}
& \Delta \mathrm{P}=\text { the pressure drop in } \mathrm{lb} / \mathrm{in}^{2} \text { across the resin bed } \\
& \mathrm{V}=\text { the column volume flow rate in } \mathrm{ml} / \mathrm{min} \\
& \mathrm{L}=\text { the column length (i.e., resin bed depth) in } \mathrm{cm} \\
& \mathrm{A}=\text { the inside cross sectional area of the column in } \mathrm{cm}^{2} \\
& \mathrm{k}=\text { is a constant characteristic of the resin particle size, particle size distribution, and particle shape. }
\end{aligned}
$$




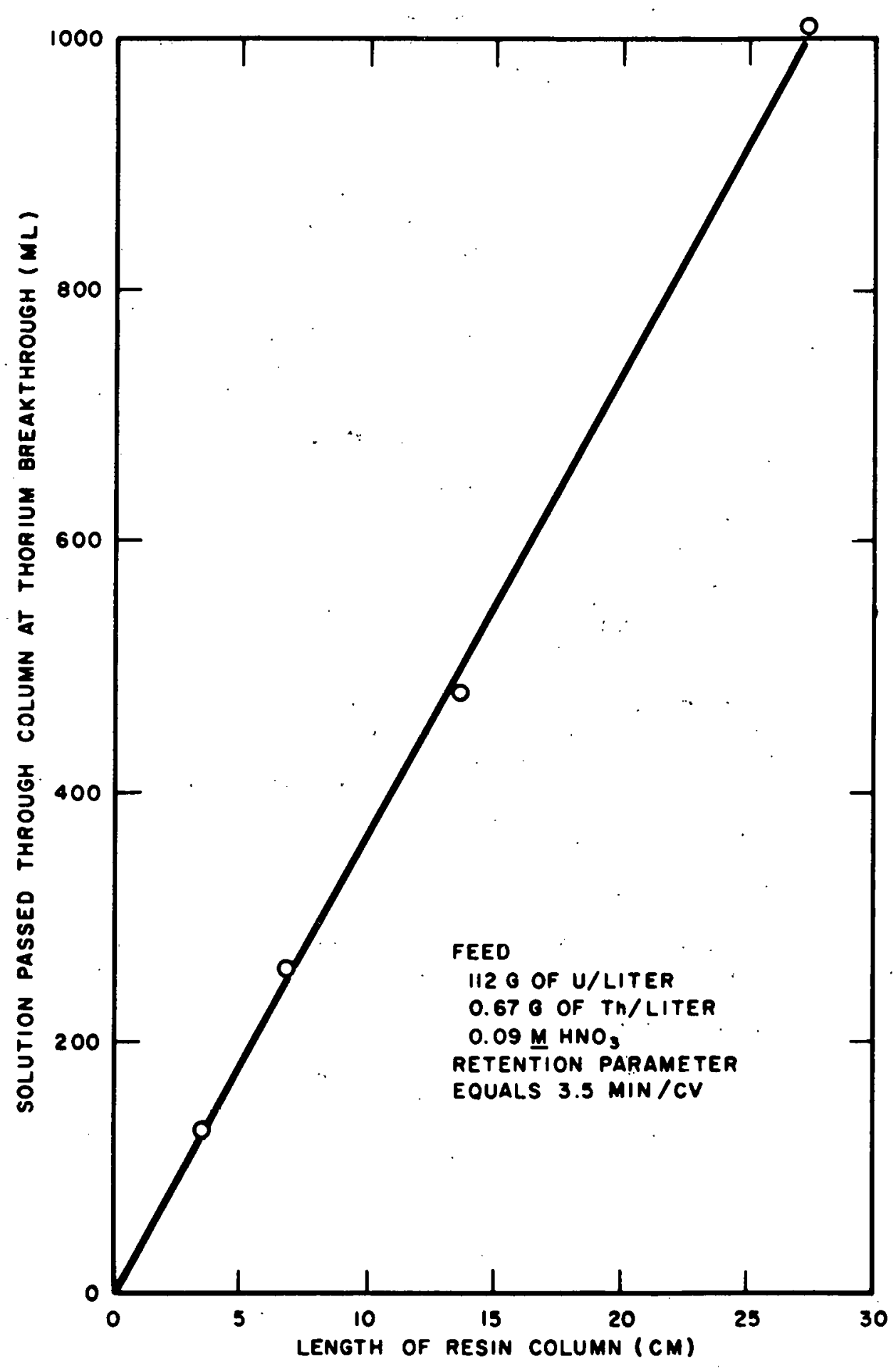

Figure 6. Effect of Column Length on the Thorium Loading Capacity of a Resin Column. 
The plot of $\Delta \mathrm{P} \mathrm{lb} / \mathrm{in}^{2}$ vs $\mathrm{V} \mathrm{ml} / \mathrm{min} \times \mathrm{L} \mathrm{cm} / \mathrm{A} \mathrm{cm}^{2}$ for each of several resins, obtained at various volume flow rates in $0.9 \mathrm{~cm}$ ID columns of varying length, is shown in Figure 7 . The slope of each line is the characteristic constant $k$ of the resin for which the line is a plot. The smaller the $k$, the smaller is the flow resistance of the resin. For the Bio Rad AG-50W-X12 (200-400 mesh) resin, the characteristic constant $k$ was smaller than for any other of the resins tested, with the value

$$
k=0.07 \frac{\mathrm{lb} / \mathrm{in}^{2}}{\left(\frac{\mathrm{ml}}{\mathrm{min}}\right)\left(\frac{\mathrm{cm}}{\mathrm{cm}^{2}}\right)}
$$

Figure 8, applicable only to 200 to 400 mesh Bio Rad AG-50W-X12 resin, is an extension of the corresponding plot in Figure 7 to larger column sizes. This pressure drop correlation was used to determine the 150 psi pressure drop requirement of the production size ion exchange column. The high pressure drop across the resin bed of the production size ion exchange column had an associated benefit. Gas bubbles entrained in the feed solution were dissolved at the high pressure in the ion exchange column. As a result, gas pockets and channeling in the resin bed were eliminated, with improvement in the column operation.

\section{Production Scale Ion Exchange Decontamination and Purification Process}

Based upon the developmental study results, cation exchange with the 2no to 400 mooh Bio Rad AG.50W$\mathrm{X} 12 \mathrm{z}$ resin was specified as the reference process for decontaminating and purifying the uranium-233 for conversion to ${ }^{233} \mathrm{UO}_{2}$. Each ion exchange run was required to be capable of pioducing 20 kilograms of decontaminated uranium-233 from a feed solution of uranyl nitrate that was $0.4 \mathrm{M}$ or less in nitric acid and zontained $120 \pm 10$ grams of uranium, with as much as 1 gram of thorium per kilogram of uranium. The production scale ion exchange decontamination and purification process, including the preparation of the process feed solutions, is discussed below and is shown schematically in Figure 9.

1. Sources of Ion Exchange Process Feed. The main source of the feed solution for the ion exchange decontamination process was the uranyl nitrate solution in ORNL tank storage, which contained approximately 250 grams of uranium per liter. This stored uranyl nitrate solution had either been received as such from HW or had been made by dissolving the SRP oxide mixture in initially $12 \mathrm{M}$ nitric acid to yield a residual acidity of $0.5 \mathrm{M}$ or less following adjustment. Volumes of uranium-233 solution from the various storage tanks were blended to yield a composite solution that met the uranium isotopic requirements of Table 3. This composite solution was diluted with high purity water, that had a specific resistance (SR) of 3.5 $\times 10^{5} \mathrm{ohm}-\mathrm{cm}$ or greater, to yield the uranium concentration and nitric acid molarity specified for the ion exchange process feed.

An additional source of feed solution for the ion exchange decontamination and purification proceec wao the uranium-233 reçovered as uranyl nitrate solution from Bettis jisap anl lium ORNL scrap and ion exchange column eluate. The uranium-233 scrap consisted of the following:

a. Batches of ${ }^{2} 3^{\prime} 3 \mathrm{UO}_{2}$ prepared in developmental studies at $\mathrm{ORNL}$ or ${ }^{233} \mathrm{UO}_{2}$ product which did not meet the specifications of Table 3

b. Binary $\mathrm{ThO}_{2}{ }^{233} \mathrm{UO}_{2}$ powder or pellets prepared in developmental studies at Bettis or product which did not meet the pellet specifications for use in the LWBR core

c. Bettis manufacturing scrap, mainly the swarf of $\mathrm{ThO}_{2}{ }^{233} \mathrm{UO}_{2}$ and abrasive particles from renterloss grinding ul the pellets. The oll or other organic material associated with the swarf was removed at Bettis by incineration in a $\mathrm{CO}_{2}$ atmosphere.

2. Uranium Recovery From Scrap. The scrap was dissolved and processed at ORNL for recovery of the uranium-233 as uranyl nitrate. The ${ }^{23} \mathrm{UO}_{2}$ scrap was dissolved in $12 \mathrm{M}$ nitric acid and adjusted to a concentration of not more than 250 grams nf uranium per litor, with a residual uilsic auld concentration of $0.5 \mathrm{M}$ or less. Dilution of this solution with high purity water yielded a feed solution for the ion exchange process which contained $120 \pm 10$ grams of uranium per liter and was less than $0.4 \mathrm{M}$ in nitric acid.

The scrap $\mathrm{ThO}_{2}{ }^{-233} \mathrm{UO}_{2}$ pellets, comminuted by jaw crusher, and the pellet grinding swarf were dissolved with a heel under reflux at $117 \mathrm{C}$ in boiling dissolvent that was $13 \mathrm{M}$ in nitric acid, 0.03 to $0.04 \mathrm{M}$ in sodium fluoride, and $0.1 \mathrm{M}$ in aluminum nitrate. The dissolution yielded a drain-off solution approximately $9 \mathrm{M}$ in nitric acid and $\mathrm{l} \mathrm{M}$ in thorium, with a $\mathrm{Th} / \mathrm{U}$ ratio of 17 or greater. Boiling off the nitric acid and diluting the 


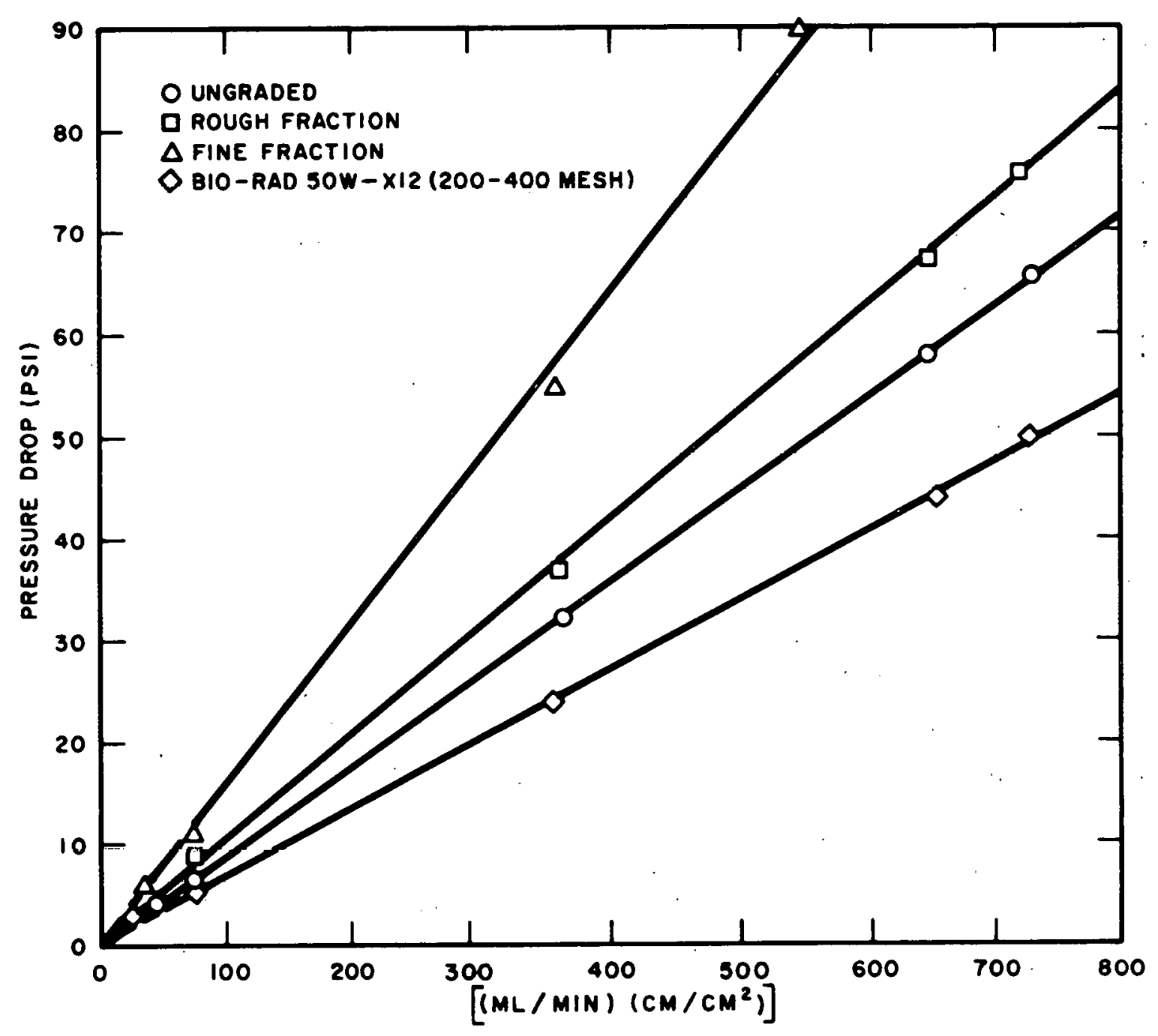

Figure 7. Pressure Drops Produced at 25C with Different Types and Sizes of Resin Under Various Flow Conditions. ( $T$ he columns were $0.9 \mathrm{~cm}$ in diameter and varied from 1 to $66 . \mathrm{cm}$ in length.) 


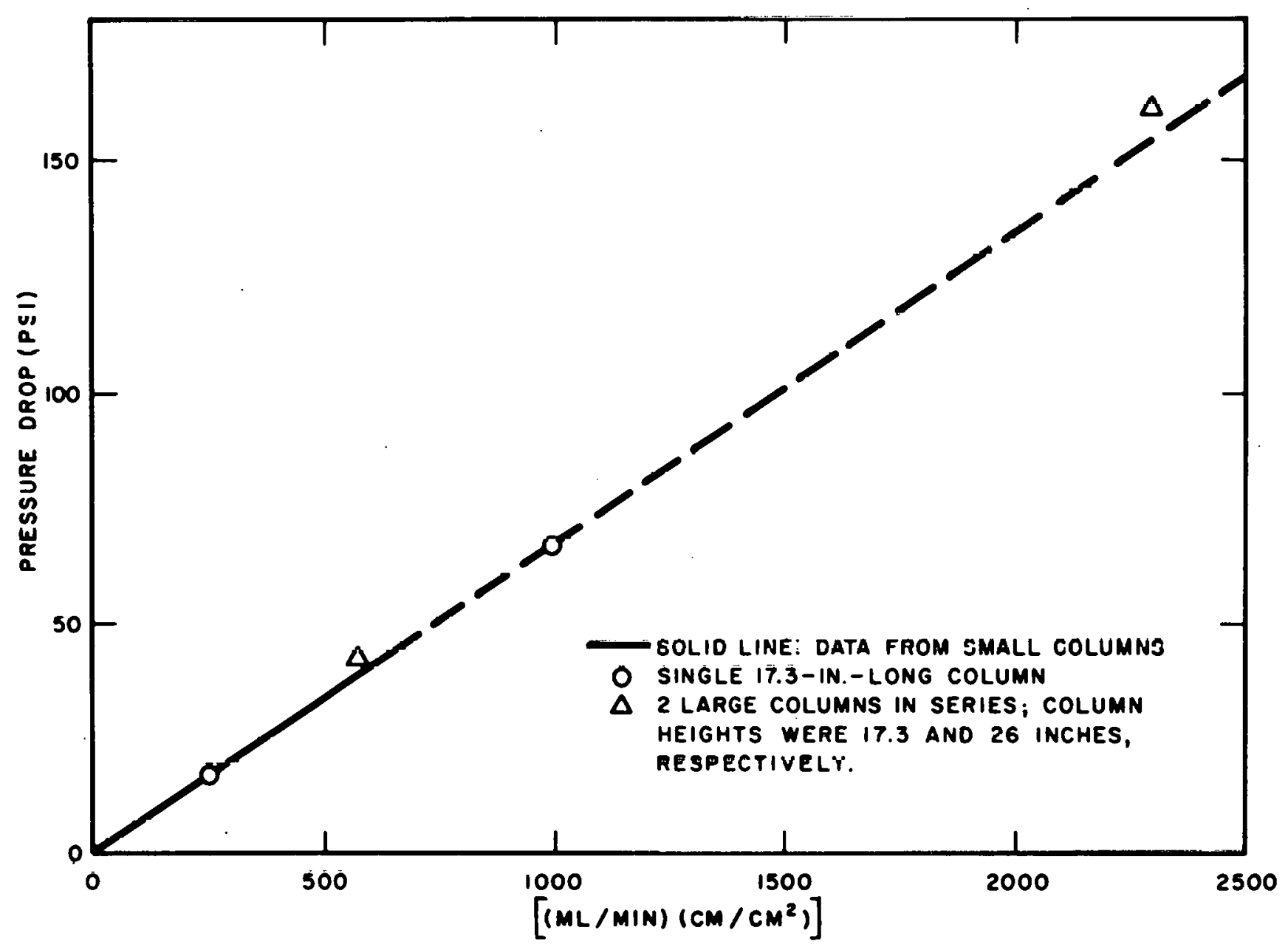

Figure 8. Comparison of Pressure Drop Data Obtained with AG-50W-X12 (200-400 mesh) Resin at 25C, U sing Both Laboratory-Scale and Large Columns. (Diameter of large columns $=3$ in.) 


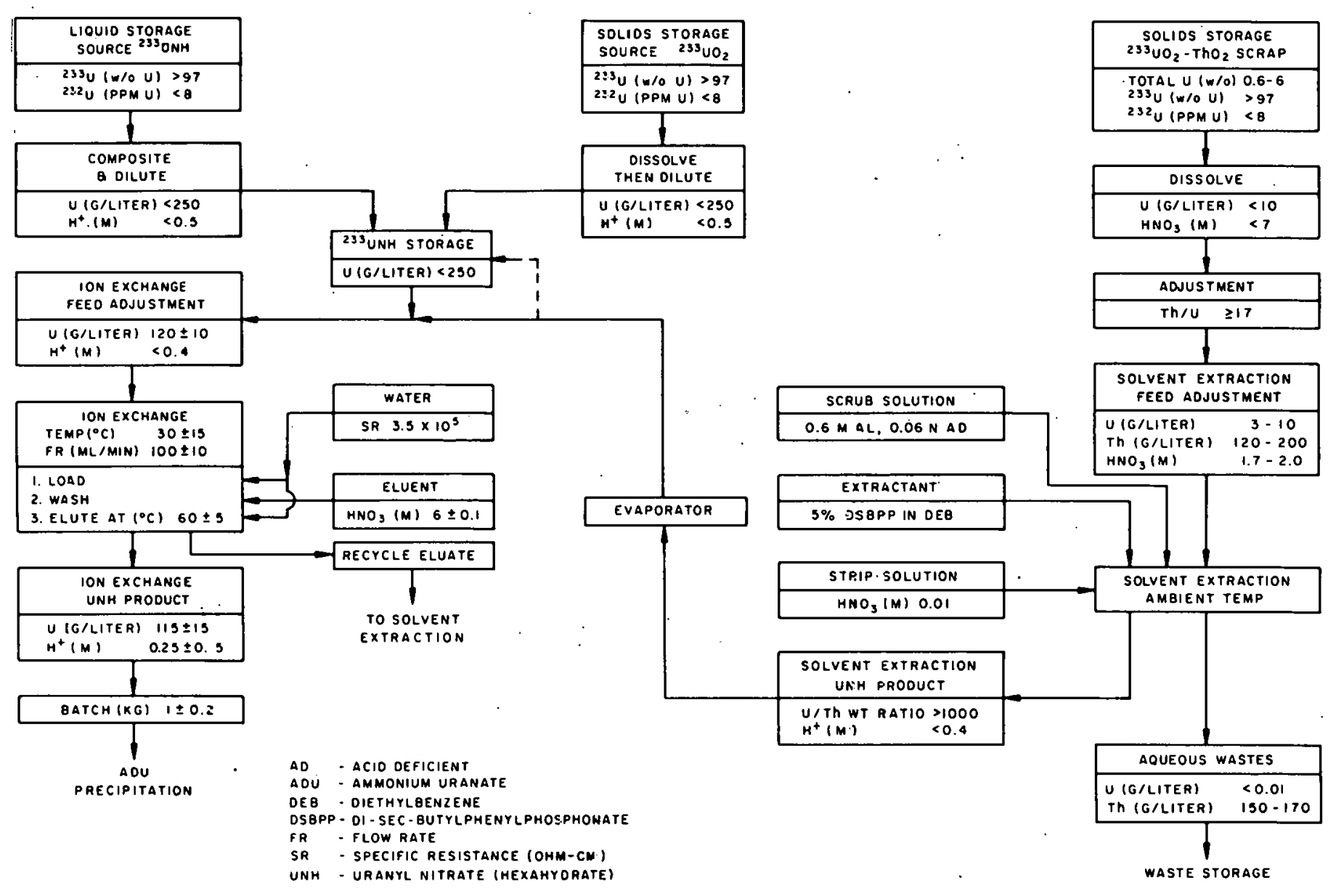

Figure 9. Production Scale Ion Exchange Decontamination and Purification Process, Including Preparation of Process Feed Solutions. 
resulting concentrate with high purity water adjusted the drain-off to a solution 1.7 to $2 \mathrm{M}$ in nitric acid, containing 120 to 200 grams of thorium and 3 to 10 grams of uranium per liter, suitable for the recovery of the uranium by solvent extraction.

Solvent extraction to recover the dissolved scrap uranium was carried out by a standard ORNL procedure. In a pulse column, the uranium was extracted into a 5 percent solution of di-sec-butylphenylphosphonate (DSBPP) in diethylbenzene (DEB) diluent and scrubbed with a $0.6 \mathrm{M}$ aluminum nitrate solution that was $0.06 \mathrm{~N}$ acid deficient (AD). Taking the uranium into the organic phase separated it from the thorium and other impurities, which were retained in the aqueous phase. The uranium was then stripped from the organic phase with $0.01 \mathrm{M}$ nitric acid. The strip solution was adjusted (by evaporation, as required) either to a concentrate of approximately 250 grams of uranium per liter for tank storage or to a feed solution for the ion exchange process. This feed solution contained $120 \pm 10$ grams of uranium per liter, with up to $1 \mathrm{gram}$ of thorium per kilogram of uranium, and was no more than $0.4 \mathrm{M}$ in nitric acid.

The ion exchange column eluate was also fed into the solvent extraction column along with the $\mathrm{ThO}_{2}$ ${ }^{233} \mathrm{UO}_{2}$ scrap feed solution for recovery of its uranium in the form ol a uranyl nitrate feed solution for the ion exchange process. The aqueous thorium nitrate from the solvent extraction was sent to waste storage.

3. Ion Exchange Production Process Operations. The production ion exchange decontamination and purification of the uranium-233 solution were carried out as indicated in the leftmnst column of operations in Figure 9. The production ion exchanger contained 6 liters of Bio Rad AG-50W-X12 (200-400 mesh) cation exchange resin in two 3 -inch diameter columns in series. The first column contained 2.5 liters of the resin (the primary resis bed) and the second column, 3.5 liters (the secondary resin bed). The ion exchange equipment was installed on a rack with remotely operable valves, and with provision for removing and replacing the resin in each column by a remotely operable water jet.

A gamma-radiation scanner was devised to follow the thorium loading front in the primary resin bed in the first column by detecting the $2.6 \mathrm{Mev}$ decay gamma-photon of the thallium-208 daughter of thorium-228. The gamma-scanner was used to assure that, in the ion exchange process, the thorium loading occurred on the primary resin bed only and did not proceed beyond it into the second column. Under process operating conditions, the thorium loading capacity of the primary resin bed was 70 grams of thorium by measurement. In a test run with a solution of two-year-old uranium-233, it was observed that after 90 grams of thorium had been loaded onto the resin, such that the thorium loading front had progressed into the second column, radium- 224 activity broke through from the secondary resin bed into the effluent product stream.

The total uranium capacity of the combined two resin beds was 1.6 kilograms. Consequently, this amount of uranium had to be loaded on to the resin before the decontaminated and purified uranium-233 appeared in the effluent product stream. Also, at the end of an ion exchange run, this 1.6 kilograms of uranium remained attached to the resin following the water wash that displarent the uranium-233 oolution frivin llie resln bed voids into the product stream. To yield the specified 20 kilograms of uranium per run, it was necessary to process a volume of feed solution (approximately 200 liters) that contained 22 kilograms of uranium. In regenerating the resin after a run, $6 \mathrm{M}$ nitric acid at $60 \mathrm{C}$ was passed through the columns to elute the uranium and the impurities. The eluate was recycled to solvent ortraction to recover the uranlum. Thus in the production ion exchange process, 9 percent of the uranium in the feed was resycled.

The production ion exchange process was carried out in the three following steps (Figure 9):

a. Load: The resin was loaded with the uranium which then broke through to yield a uranlum product practically free of thorium (both thorium-232 and thorium-228) and of radium-224, but which retained about half of the initial lead-212 content. The feed solution flow rate during the loading (decontamination and purification) step was approximately 0.1 liter per minute at a pressure up to 150 pẹi.

b. Wash: The uranium-233 feed solution left in the resin bed voids was washed into the product stream with high purity water.

c. Elute: The uranium and impurities held on the resin were eluted and recycled to solvent extraction to recover the uranium. The $6 \mathrm{M}$ nitric acid eluent at $60 \mathrm{C}$ removed all of the uranium, lead, and radium, and also any transition metal impurities that were exchanged onto the recin from the nraniun-233 feed sulutiun. However, the eluent removed only about 50 percent of the thorium. By having the eluent flow in the primary resin bed countercurrent to the feed solution flow, the residual uneluted thorium was pushed back toward the inlet of the ion exchange system. This restrained the thorium loading front from progressing beyond the primary resin bed into the secondary bed in the second column during the ensuing loading step of the next run. 
The six sequential operations to carry out these three production ion exchange process steps followed the flowsheet of Figure 2, which gives the solution temperatures and expresses their flow rates and flow volumes in terms of column volumes. The compositions of the production ion exchange process solutions, however, were as given in Figure 9 and in Table 11.

\section{E. Plant Scale Evaluation of Production Ion Exchange Process}

A series of three demonstration runs was made with the installed plant equipment as a proof test of the ion exchange decontamination and purification process. The feed solutions were prepared from uranium-233 (in the form of uranyl nitrate) containing $8 \mathrm{ppm}$ of uranium-232, whose decay products had been accumulating for periods of time ranging from 140 days to two years. Also the feed solutions contained from 8 to 1000 milligrams of thorium per kilogram of uranium-233. The high thorium concentration corresponded to the maximum thorium concentration in the ion exchange feed solution obtained from solvent extraction of dissolved $\mathrm{ThO}_{2}{ }^{233} \mathrm{UO}_{2}$ scrap. Each of the ion exchange process runs was carried out according to the sequence of operations outlined in Figure 2.

All three demonstration runs gave essentially the same results. They confirmed that the ion exchange decontamination and purification process yielded a uranium product suitable for conversion to ${ }^{233} \mathrm{UO}_{2}$ for use at Bettis in the semiremote fabrication of the LWBR fuel. Generally illustrative of all the runs, Figure 10 presents the experimental data from one run made with a feed solution that contained $19.1 \mathrm{kilog} r a m s$ of twoyear-old uranium-233, with 1 gram of thorium per kilogram of uranium-233. This run yielded $17 \mathrm{kilograms}$ of uranium-233 pröduct which was collected and stored in two portions. One portion contained the first 10 kilograms of the uranium 233 effluent product, and the other the final 7 kilograms. The variation with time of the gamma-activity of each of the product portions was followed by gamma-counting samples at regular intervals.

Both effluent product portions contained less than 10 milligrams of thorium per kilogram of uranium-233, showing that the process removed more than 99 percent of the high thorium concentration. The gammaactivity of the effluent product portions is plotted in Figure 10 as the ratio of the activity of the thallium-208 daughter in the product to the activity of thallium-208 in equilibrium with the amount of uranium-232 in the product. From the count data, the gamma-activity of the first portion of the effluent product decreased in three days to 0.11 percent of the steady state or equilibrium gamma-activity level. The gamma-activity of the second portion decreased in four days to 0.15 percent of the steady state gamma-activity level.

The horizontal line on the plot in Figure 10 indicates 2 percent of the steady state level of the gammaactivity in the effluent product solution. Brooksbank, Nichols, and Lotts (Reference ll) have shown that uranium-233 containing 8 ppm of uranium-232 can be processed in an alpha facility without special gamma-shielding, with personnel exposures of less than 40 mrem per man-week, provided that the gammaactivity of the uranium-232 daughters does not exceed 2 percent of the steady state value. Reference to Figure 10 shows that within one day after undergoing the production ion exchange process, the gammaactivity of the product solution decayed to less than 2 percent of the steady state level, and it remained below this level for the next 24 days.

\section{CONVERSION OF URANIUM-233 TO URANIA $\left({ }^{233} \mathrm{UO}_{2}\right)$}

The uranium-233, in the form of the uranvl nitrate effluent from the ion exchange decontamination and purification process, underwent conversion to ${ }^{233} \mathrm{UO}_{2}$ for use in fabricating the LWBR fuel. The conversion involved the following process steps:

1. Precipitation of ammonium uranate (ADU) from the recirculating uranyl nitrate solution with gaseous ammonia

2. Separation of the ADU from the mother liquor by centrifugation, with rinsing

3. Drying of the ADU precipitate in a microwave oven

4. Reduction of the $\mathrm{ADU}$ to ${ }^{233} \mathrm{UO}_{2}$ with hydrogen in a furnace

5. Stabilization of the ${ }^{233} \mathrm{UO}_{2}$

6. Blending, analysis, and packaging of the ${ }^{233} \mathrm{UO}_{2}$.

This choice of process steps was based on prior Bettis experience and a review of the literature, especially as presented by Belle (Reference 12) and Woolfrey (Reference 13). The decision to precipitate the uranium233 in the form of $A D U$ resulted from the requirement that the ${ }^{23} \mathrm{UO}_{2}$ product be semiamorphous, with the ceramic activity to promote sinterability of the $\mathrm{ThO}_{2}{ }^{233} \mathrm{UO}_{2}$ fuel pellets. The ADU precipitate was favored 


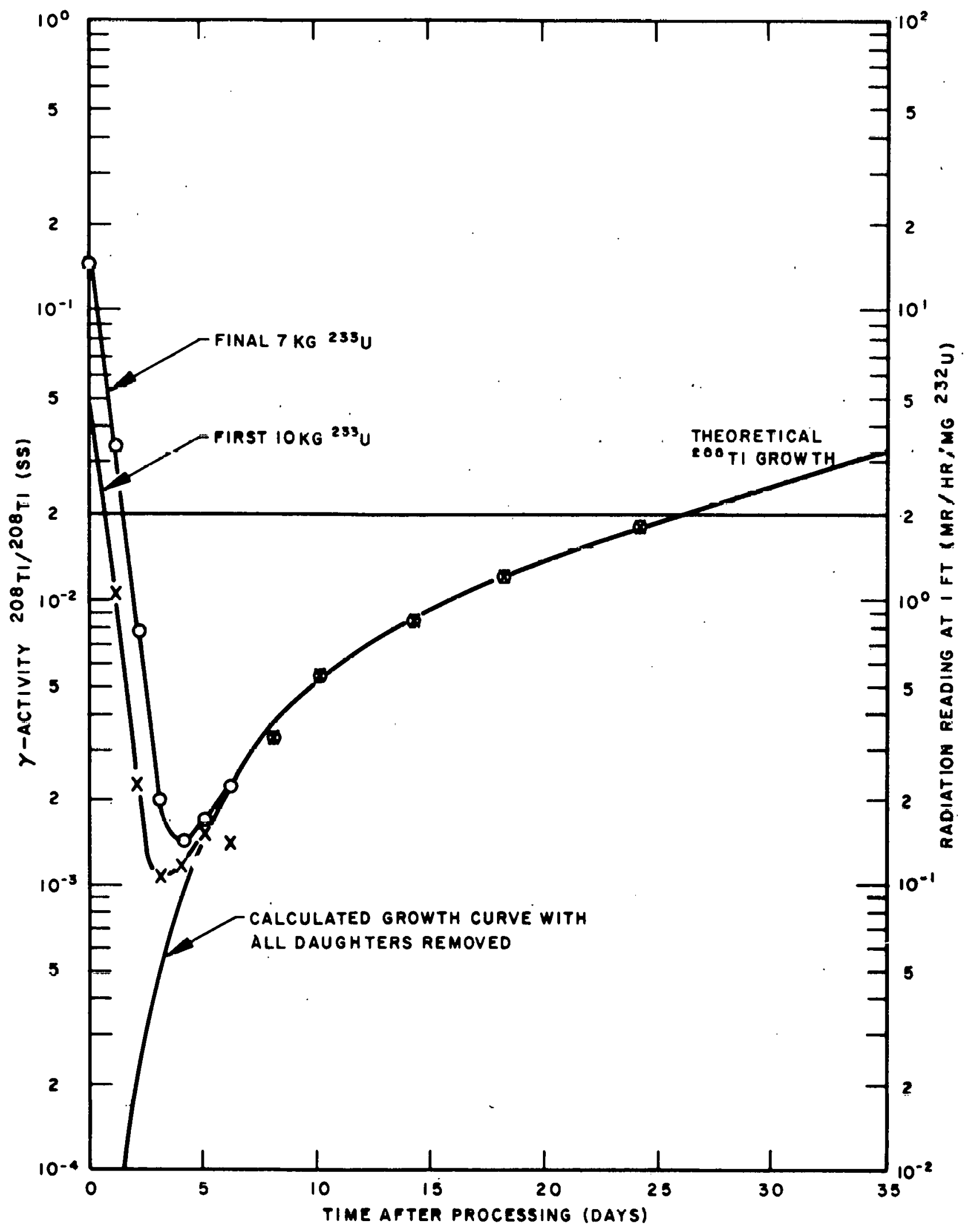

Figure 10. Transient Behavior of Gamma Activity in Product Solution From Plant Scale Ion Exchange Processing of Feed Containing 2.Year-Old Uranium-233, with 8 Milligrams of Uranium-232 and 1 Gram of Thorium per Kilogram of Uranium-233. 
because it forms in small, highly imperfect crystals whose structure is an ideal precursor for the semiamorphous ${ }^{233} \mathrm{UO}_{2}$ structure. This characteristic of the ADU precipitate, which makes it difficult to filter, indicated the use of the centrifuge for separating the ADU crystals. Because gaseous a mmonia is available at high purity and is convenient to handle, it was chosen in preference to ammonium hydroxide as the precipitant to form the ADU. The use of microwave drying, to generate heat throughout the bed of the precipitate, gave the advantage of ridding the crystals of moisture rapidly, minimizing the opportunity for recrystallization during drying.

\section{A. Urania Conversion Flowsheet Development}

To establish conditions yielding a ${ }^{23} \mathrm{UO}_{2}$ product that met the LWBR specifications, Leitnaker et al. (Reference 14) (ORNL) carried out a developmental study with the flowsheet shown in Figure 11 to determine the limits of the operational parameters of the conversion process. The initial study of the parameters was carried out with bench scale and pilot size equipment, using depleted uranium (uranium-238). A series of developmental pilot scale runs was also made with enriched uranium in order to supply ${ }^{\mathrm{E}} \mathrm{UO}_{2}$ to Bettis for a test program.

1. Precipitation of ADU. Studies reported by Cordfunke (Reference 15) and by Stuart and Whately (Reference 16) show that the ternary $\mathrm{NH}_{3}-\mathrm{UO}_{3}-\mathrm{H}_{2} \mathrm{O}$ system consists of a series of at least four distinct compounds representing various ratios of the constituent molecules. The precipitate obtained on adding ammonia to an aqueous solution of uranyl nitrate is commonly designated ammonium diuranate (ADU), with the formula $\left(\mathrm{NH}_{4}\right)_{2} \mathrm{U}_{2} \mathrm{O}_{7}$, which is equivalent to $2 \mathrm{NH}_{3}-2 \mathrm{UO}_{3}-\mathrm{H}_{2} \mathrm{O}$. However, the composition of this precipitate varies with the conditions of precipitation. A bench scale study was made to evaluate the effect of the conditions of precipitation not only upon the chemical composition of ADU (which will be used as the yeneric designation of the $\mathrm{NH}_{3}-\mathrm{UO}_{3}-\mathrm{H}_{2} \mathrm{O}$ system), but also upon the morphology of the $\mathrm{UO}_{2}$ formed by reduction of the ADU by hydrogen.

Using a uranyl nitrate solution containing 100 grams of uranium-238 per liter, a bench scale factorial experiment was run to determine the effect of the precipitation temperature, initial solution acidity, final solution $\mathrm{pH}$, and precipitate digestion time upon the composition of the microwave dried ADU and upon the specific surface area of the $\mathrm{UO}_{2}$ product. Experimental results presented in Table 6 show the wide variation in the $\mathrm{NH}_{3} / \mathrm{U}$ molar ratio of the $\mathrm{ADU}$ as a function of the precipitation conditions. The nitrate ion residual in the dried ADU precipitate was mainly in the form of ammonium nitrate $\left(\mathrm{NH}_{4} \mathrm{NO}_{3}\right)$. which was not rinsed out during the centrifuging of the precipitate. This salt is volatile, and it was removed by sublimation when the $A D U$ was reduced to $\mathrm{UO}_{2}$ in a hydrogen atmosphere at $600 \mathrm{C}$. However, to avoid depositing $\mathrm{NH}_{4} \mathrm{NO}_{3}$ in the furnace off-gas ducts, starting with the pilot scale runs and thereafter, a water rinse was included in the centrifuge operation. After transfer of the precipitate slurry to the centrifuge, a volume of water approximately equal to 75 percent of the volume of the slurry was recirculated through the precipitator and then transfered to the centrifuge as a rinse. This reduced the amount of $\mathrm{NH}_{4} \mathrm{NO}_{3}$ in the dried ADU cake by over 98 percent.

The ceramic activity (sinterability) of $\mathrm{UO}_{2}$.is related to its specific surface area. Hence the specific surface area of the $\mathrm{UO}_{2}$ was an important physical attribute from the viewpoint of the use of the $\mathrm{UO}_{2}$ in fuel pellet manufacture. This property was measured by the standard BET gas adsorption method of Brunauer, Emmet, and Teller (Reference 17). The effect of the precipitation variables on the specific surface area of the $\mathrm{UO}_{2}$ powder, as computed from the data of Table 6, was as follows:

\begin{tabular}{llc}
\multicolumn{1}{c}{$\begin{array}{c}\text { Pptn } \\
\text { Variable }\end{array}$} & \multicolumn{1}{c}{$\begin{array}{c}\text { Change in Pptn } \\
\text { Variable }\end{array}$} & $\begin{array}{c}\text { Effect on Specific } \\
\text { Surface Area of UO }\end{array}$ \\
\cline { 2 - 3 } Temperature & $22-30 \mathrm{C} \rightarrow 54-62 \mathrm{C}$ & $+0.07 \mathrm{~m}^{2} / \mathrm{g}$ \\
Initial acidity & $0.4 \mathrm{M} \rightarrow 1.4 \mathrm{M} \mathrm{HNO}_{3}$ & $+0.74 \mathrm{~m}^{2} / \mathrm{g}$ \\
Final pH & $5-6 \rightarrow 8.7-9.2$ & $-0.83 \mathrm{~m}^{2} / \mathrm{g}$ \\
Digestion time & $0-10$ inin. $\rightarrow 120 \mathrm{min.}$ & $+0.31 \mathrm{~m}^{2} / \mathrm{g}$
\end{tabular}




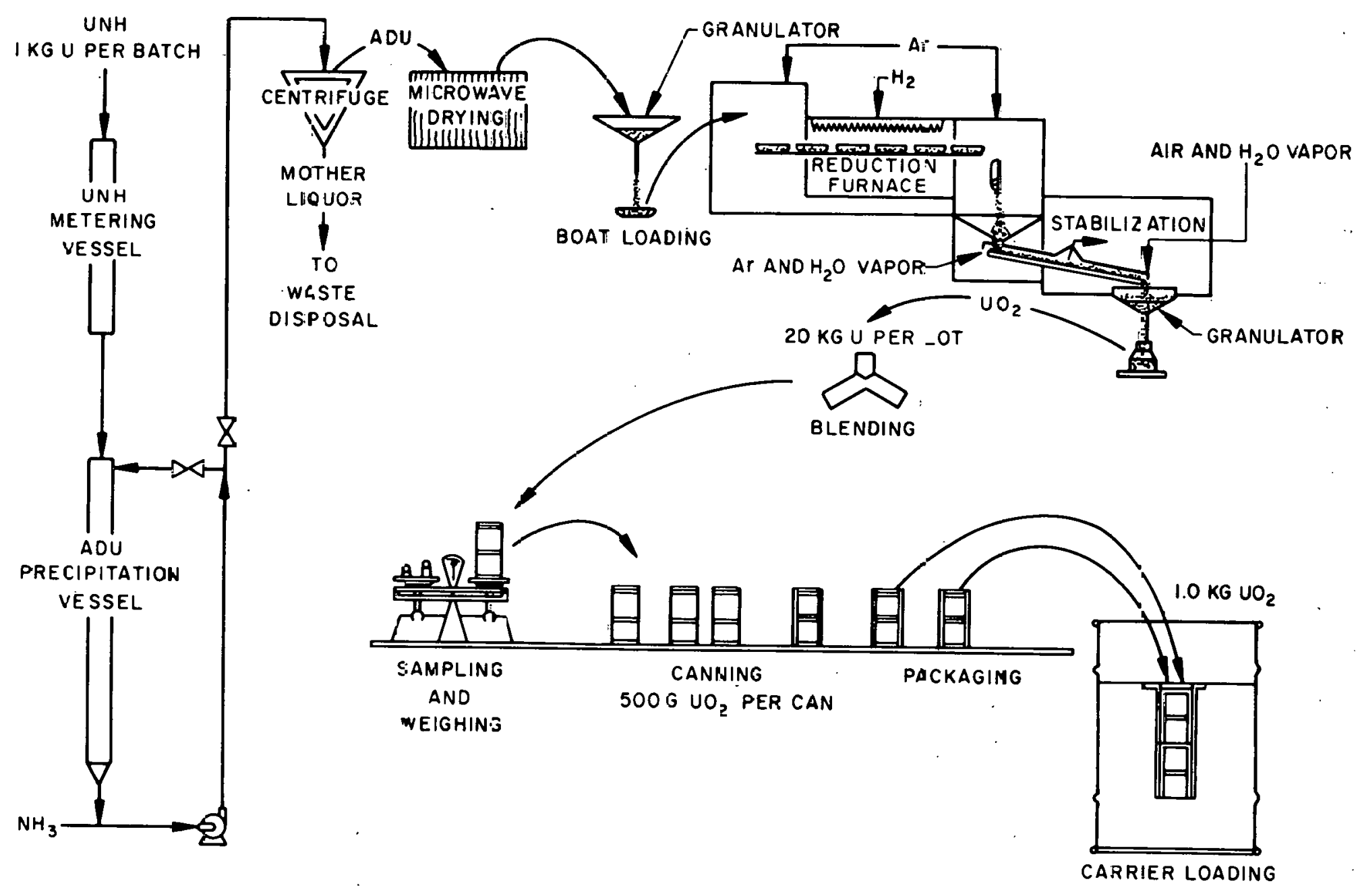

Figure 1 1. Chemica: Process Flowsheet: Production of ${ }^{233} \mathrm{UO}_{2}$ Powder UNH - Uranyl Nitrate (Hexahydrate)

ADU: Arnmonium Uranate 
TABLE 6. EFFECTS OF PRECIPITATION VARIABLES ON ADU AND UO ${ }_{2}$ POWDER

Precipitation Conditions

\begin{tabular}{|c|c|c|c|}
\hline \multicolumn{4}{|c|}{ Precipitation Conditions } \\
\hline $\begin{array}{c}\text { Temperature } \\
\text { (degrees C) } \\
\end{array}$ & $\mathrm{pH}$ & $\begin{array}{r}\mathrm{HNO}_{3} \\
(\mathrm{M})\end{array}$ & $\begin{array}{l}\text { Time } \\
\text { (min) }\end{array}$ \\
\hline $22-30$ & 5.6 & C. 4 & 0.10 \\
\hline $22 \cdot 30$ & $5-6$ & C. 4 & 120 \\
\hline 22.30 & $8.7-9.2$ & C. 4 & 0.10 \\
\hline 22.30 & $8.7-9.2$ & C. 4 & 120 \\
\hline $22-30$ & $5-6$ & I. 4 & 0.10 \\
\hline 22.30 & 5.6 & 1.4 & 120 \\
\hline 22.30 & $8.7-9.2$ & 1.4 & 0.10 \\
\hline $22-30$ & $8.7-9.2$ & J.4 & 120 \\
\hline $54-62$ & 5.6 & 0.4 & 0.10 \\
\hline 54.62 & $5-6$ & 0.4 & 120 \\
\hline $54-62$ & $8.7 \cdot 9.2$ & 0.4 & 0.10 \\
\hline $54-62$ & $8.7-9.2$ & 0.4 & 45 \\
\hline 54.62 & $8.7-9.2$ & 1.4 & 0.10 \\
\hline 54.62 & $8.7-9.2$ & $14^{\circ}$ & 120 \\
\hline 54.62 & 5.6 & 1.4 & 0.10 \\
\hline 54.62 & 5.6 & 1.4 & 120 \\
\hline
\end{tabular}

Analysis of ADU Cake ${ }^{a}$

\begin{tabular}{|c|c|c|c|c|c|c|c|c|}
\hline & \multirow{2}{*}{\multicolumn{2}{|c|}{$\begin{array}{c}\text { Surface }^{\text {Powder }} \\
\text { Alea } \\
\left(\mathrm{m}^{2} / \mathrm{g}\right) \\
\end{array}$}} \\
\hline $\begin{array}{c}\mathrm{H}_{2} \mathrm{O} \\
(w t \%)\end{array}$ & $\begin{array}{c}\mathrm{NH}_{3} \\
(w 1 \%)\end{array}$ & $\begin{array}{l}\text { Total U } \\
\text { (wt } \%)\end{array}$ & $\begin{array}{c}\mathrm{NO}_{3} \\
(\text { wt \%) }\end{array}$ & $\begin{array}{c}\mathrm{NH}_{3} / \mathrm{U} \\
\text { Mole Ratio }\end{array}$ & & $\underset{\text { Mole Ratio }}{\mathrm{NO}_{3} / \mathrm{U}}$ & & \\
\hline 14.3 & 3.38 & 62.1 & 7.69 & 0.761 & & 0.475 & 7.88 & . \\
\hline 5.3 & 3.50 & 69.2 & 8.05 & 0.708 & $\therefore$ & 0.447 & 8.49 & \\
\hline 14.1 & 3.94 & 62.2 & 7.17 & 0.887 & & 0.443 & 8.00 & \\
\hline 17.8 & 3.73 & 65.3 & 6.10 & 0.740 & & 0.252 & 8.25 & \\
\hline 14.4 & 4.05 & 59.4 & 10.20 & 0.955 & & 0.659 & $7: 47$ & \\
\hline 5.35 & 4.17 & 66.5 & 10.56 & & & & 8.08 & \\
\hline 36.1 & 3.54 & 44.0 & 7.44 & 1.130 & & 0.649 & 7.56 & \\
\hline 31.9. & 3.81 & 47.8 & 6.80 & 1.120 & & 0.546 & 6.05 & \\
\hline 12.7 & 2.76 & 66.5 & 4.62 & 0.581 & . & 0.267 & 6.24 & \\
\hline 10.0 & 2.98 & 68.6 & 4.57 & 0.608 & & 0.256 & 7.25 & \\
\hline 12.3 & 3.03 & 66.4 & 4.87 & 0.639 & & 0.281 & 7.20 & \\
\hline 7.1 & 2.95 & 71.8 & 3.68 & 0.575 & & 0.197 & 5.82 & \\
\hline 21.5 & . 3.39 & 57.9 & 5.58 & 0.820 & & 0.370 & 6.07 & \\
\hline 8.0 & 3.30 & 69.4 & 5.29 & 0.666 & & 0.292 & 9.82 & \\
\hline 11.4 & 3.02 & 65.6 & 6.76 & 0.644 & & 0.395 & 10.4 & \\
\hline 12.1 & 2.97 & 65.7 & 6.00 & 0.632 & & 0.350 & 9.57 & \\
\hline
\end{tabular}

aDrying cycle: $78 \mathrm{C}$ for 15 min.; $100 \mathrm{C}$ for $4.5 \mathrm{~min}$. (microwave oven); $\mathrm{H}_{2} \mathrm{O}$ obtained by difference.

beduction sycle was room temperature to $600 \mathrm{C}$ at $200 \mathrm{C} / \mathrm{hr}$, hold $5.5 \mathrm{hr}$, furnace cocl. First $3.1 / 2 \mathrm{hr}$ in Ar at 0.4 liter $/ \mathrm{min}$; the remainder of the t:me in $\mathrm{H}_{2}$ at 0.4 liter/min. Samples were all taken from the center portion of the furnace where the thermocouple was. 
The interaction of the precipitation variables was in some cases synergistic. Thus the combination of high final $\mathrm{pH}$ (that is, high final ammonia concentration) and high initial acidity decreased the specific surface area of the $\mathrm{UO}_{2}$ by 0.68 square meters per gram, while the combination of high solution temperature and high initial acidity increased it by 1.60 square meters per gram. The data show that varying the precipitation parameters within the limits indicated in Table 6 caused a variation in the specific surface area of the $\mathrm{UO}_{2}$ over the range from 5.82 to 10.4 square meters per gram.

2. Microwave Drying of ADU. A series of bench scale runs was made to determine the effect of the microwave drying conditions upon the composition and specific surface area of the ADU and upon the specific surface area of the $\mathrm{UO}_{2}$ formed from it. For these runs the ADU was precipitated with gaseous ammonia from a uranyl nitrate solution $0.4 \mathrm{M}$ in nitric acid, containing 100 grams of uranium-238 per liter. The ADU precipitate was centrifuged for 2 minutes at $600 \mathrm{~g}$ prior to drying. The conditions of precipitation and of reduction were standardized as outlined in the footnotes of Table 7, which presents the conditions and results of this study.

The experimental data show that increasing the temperature and time of drying resulted in a greatly increased removal of water and a slightly increased removal of ammonia from the ADU. Increasing the drying temperature and time also decreased the specific surface area of the ADU, but slightly increased the specific surface area of the $\mathrm{UO}_{2}$. Grinding the dried $\mathrm{ADU}$ and the $\mathrm{UO}_{2}$ had no significant effect upon the specific surface area of the $\mathrm{UO}_{2}$. In general, varying the drying cycle parameters within the limits of this study had but small effect upon the specilic surface area of the final $\mathrm{UO}_{2}$ product.

3. Reduction of ADU to $\mathrm{UO}_{2}$. A thermogravimetric analysis was made of the reduction of ADU to compare reducing atmospheres of 100 percent hydrogen and 4 percent hydrogen in argon. Small samples of dried ADU (shown by $\mathrm{X}$-ray diffraction to be actually $\mathrm{NH}_{3}-2 \mathrm{UO}_{3}-3 \mathrm{H}_{2} \mathrm{O}$ ) made from uranium-238 were heated to $700 \mathrm{C}$ at the rate of $2 \mathrm{C}$ per minute, with observation of the cumulative weight change. The analysis results, plotted in Figure 12, show that rapid reduction to $\mathrm{UO}_{2}$ occurred at 350 to $425 \mathrm{C}$ in 100 percent hydrogen and at 425 to $550 \mathrm{C}$ in 4 percent hydrogen in argon. The physical and chemical properties of the two $\mathrm{UO}_{2}$ powder products were measured. These properties included the oxygen-to-metal (O/M) atom ratio, tap density, specific surface area (BET), porosity, and average particle diameter. The porosity and average particle diameter were measured by the gas permeability method using the Fisher sub-sieve sizer (FSS) (Reference 18). The characterization of the two $\mathrm{UO}_{3}$ powder products, which is recorded in Table 8, shows that the $\mathrm{UO}_{2}$ from reduction in 100 percent hydrogen had a larger specific surface area and a smaller particle size and tap density than the product reduced in the 4 percent hydrogen-in-argon atmosphere.

Scanning electron micrographs made of the two $\mathrm{UO}_{2}$ powders from the thermogravimetric analysis corroborated that reduction in 100 percent hydrogen yielded a smaller particle size than reduction in a mixture of 4 percent hydrogen in argon.

A pilot scale study of furnace reduction cycles for converting $\mathrm{ADU}$ to $\mathrm{UO}_{2}$ was made with a small programmable Inconel tube furnace using a reducing atmosphere of 100 percent hydrngen, which preced. ing studies had indicated to be the more lavorable reductant. The effect of the cycle upon the specific surface area of the $\mathrm{UO}_{2}$ was determined. The ADU samples, which had been precipitated with gaseous ammonia from a solution that was $0.4 \mathrm{M}$ in nitric acid and contained 100 grams of uranium per liter, were centrifuged, dried by microwave, and charged into the tube furnace in Inconel boats. During furnace heatup, argon at a flow rate of four system volumes per minute was passed through the furnace. Then automatically, at the specified time in the cycle, the argon flow was discontinued, and hydrogen at the same flow rate was passed into the furnace to displace the argon and maintain a reducing atmosphere. At the end of the furnace cycle, the $\mathrm{UO}_{2}$ was permitted to cool in the hydrogen atmosphere of the furnace. Table 9 outlines the cycle conditions and the results.

The experimental data show that varying the parameters of the furnace reduction cycle caused a variation in the specific surface area of the $\mathrm{UO}_{2}$ from 4.0 to 20.7 square meters per gram. The effect of the furnace reduction cycle upon the surface area of the $\mathrm{UO}_{2}$ was far greater than the effect of any other step in the conversion process. The higher the furnace temperature when the hydrogen was admitted, the smaller was the specific surface area of the $\mathrm{UO}_{2}$. This effect is considered to be indicative of microsintering at the high temperature reduction.

4. Stabilization of $\mathrm{UO}_{2}$. Exposing freshly reduced $\mathrm{UO}_{2}$ directly to the air results in the immediate chemisorption of a monolayer of oxygen on its surface, with the evolution of approximately 30 kilocalories of heat per mole of oxygen. In the case of $\mathrm{UO}_{2}$ powder with a high specific surface area, the evolved heat, if not 
TABLE 7. EFFECTS OF DRYING CYCLE VARIABLES ON ADU AND UO ${ }_{2}$

\begin{tabular}{|c|c|c|c|c|c|c|c|c|c|c|c|}
\hline \multirow[b]{3}{*}{$\begin{array}{c}\text { Temperature } \\
\text { (degrees C) }\end{array}$} & \multirow[b]{3}{*}{$\begin{array}{l}\text { Time } \\
(\min )\end{array}$} & \multirow[b]{3}{*}{ Ground } & \multicolumn{8}{|c|}{ ADU } & \multirow{3}{*}{$\begin{array}{c}\mathrm{UO}_{2} \\
\text { Reduced Oxide }^{\mathrm{c}} \\
\text { Surface Area } \\
\left(\mathrm{m}^{2} / \mathrm{g}\right)\end{array}$} \\
\hline & & & \multirow[b]{2}{*}{$\begin{array}{r}\mathrm{NH}_{3} \\
(w+\%) \\
\end{array}$} & \multirow[b]{2}{*}{$\begin{array}{l}\mathrm{H}_{2} \mathrm{O}^{\mathrm{a}} \\
(w+\%)\end{array}$} & \multirow[b]{2}{*}{$\begin{array}{c}U \\
(w t \%)\end{array}$} & \multirow[b]{2}{*}{$\begin{array}{r}\mathrm{NO}_{3} \\
\text { (wt \%) } \\
\end{array}$} & \multirow{2}{*}{$\begin{array}{c}\mathrm{NH}_{3} / \mathrm{U} \\
\text { Mole } \\
\text { Ratio }\end{array}$} & \multicolumn{3}{|c|}{ Surface Area ${ }^{b}$} & \\
\hline & & & & & & & & $\begin{array}{l}\text { Case } 1 \\
\left(\mathrm{~m}^{2} / \mathrm{g}\right)\end{array}$ & $\left(m^{2} / g\right)$ & $\begin{array}{c}\text { Case } 2 \\
\left(\mathrm{~m}^{2} / \mathrm{g} \text { of } U\right)\end{array}$ & \\
\hline 78 & 45 & Yes & 3.22 & 18.9 & 60.5 & 5.2 & 0.741 & 7.87 & 8.60 & 14.2 & 5.69 \\
\hline 78 & 45 & No & & & & & & & & & 5.74 \\
\hline 78 & 80 & Yes & & & & & & & & & \\
\hline 78 & 80 & No & 3.21 & 10.7 & 66.9 & 5.7 & $0.67 \dot{2}$ & 5.25 & 7.06 & 10.6 & 5.94 \\
\hline 115 & 45 & Yes & & & & & & & & & 5.98 \\
\hline 115 & 45 & No & 3.18 & 5.8 & 70.7 & & 0.630 & 5.23 & 5.58 & 10.0 & 5.42 \\
\hline 115 & 80 & Yes & & & & & & & & & 5.51 \\
\hline 115 & 80 & No & & & & & & & & . & \\
\hline & & & 3.16 & 2.7 & 73.4 & 6.2 & 0.603 & 4.10 & 5.12 & 7.1 & 6.69 \\
\hline & & & & & & & & & & & 6.70 \\
\hline
\end{tabular}

$\bar{~}{ }^{\mathrm{W}} \mathrm{W} \times \mathrm{H}_{2} \mathrm{O}$ calculated by subtracting wt $\% \mathrm{U}\left(\mathrm{as} \mathrm{UO}_{3}\right.$ ), $\mathrm{NO}_{3}$ (as $\mathrm{HNO}_{3}$ ), and bound $\mathrm{NH}_{3}$ from $100 \%$.

${ }^{b}$ Case $l$ is a sample that was degassed $30 \mathrm{~min}$. $n$ vacuum at $120 \mathrm{C}$. Case 2 is a sample that was degassed 50 min in vacuum at 60C.

'Precipitation cycle: $100 \mathrm{~g} \mathrm{U} / \mathrm{liter}, 0.4 \mathrm{M} \mathrm{HNO}_{3}$ at ambient temperature (rising $1042 \mathrm{C}$ ) to $\mathrm{pH} 8.0$; no digestion.

Reduction cycle: $600 \mathrm{C}$ at $20.0 \mathrm{C} / \mathrm{hr}$; hold $5 \mathrm{hr}$ and cool. First $31 / 2 \mathrm{hr}$ in argon at $0.4 \mathrm{liter} / \mathrm{min}$, then $\mathrm{H}_{2}$ at $0.4 \mathrm{liter} / \mathrm{min}$ 


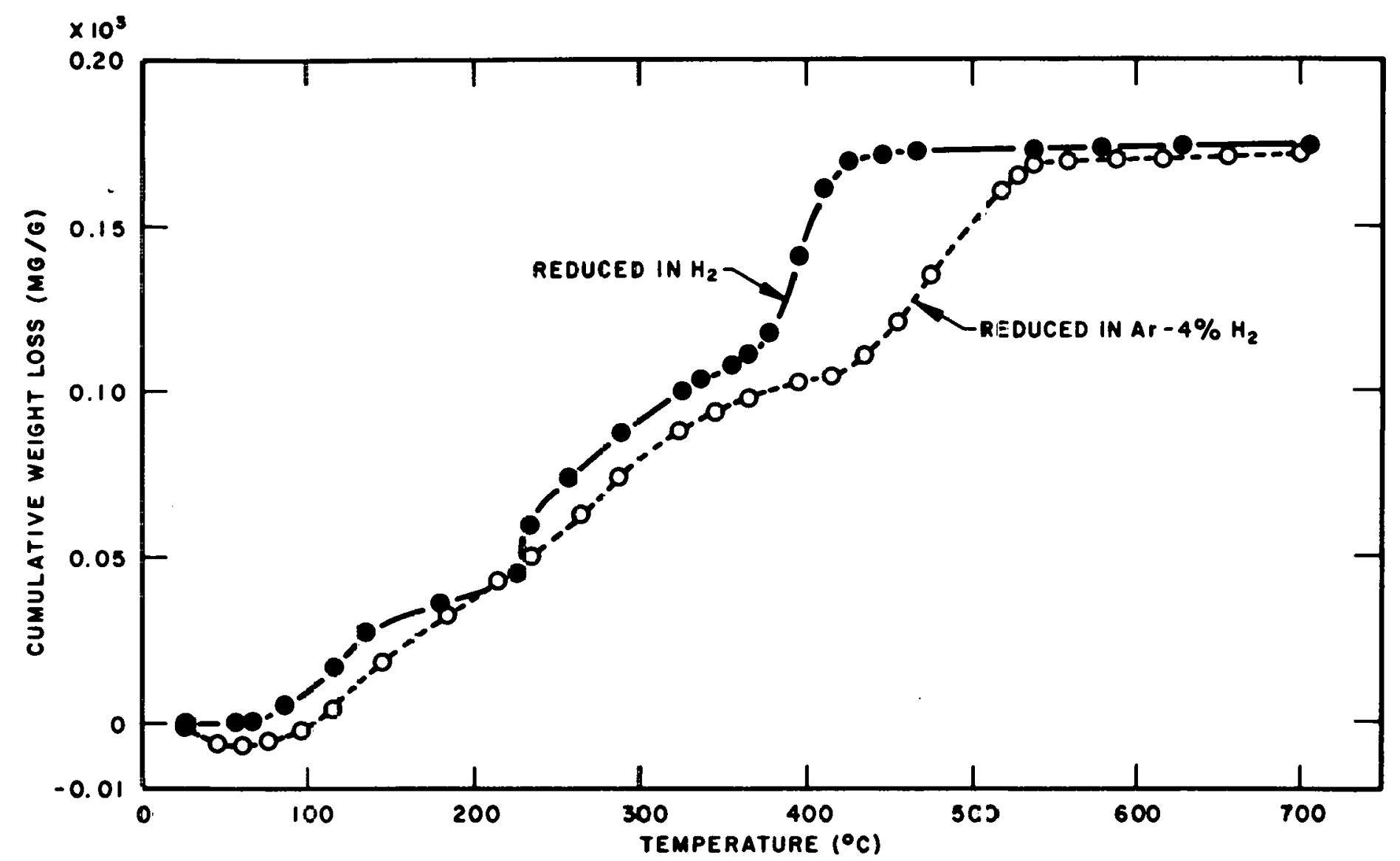

Figure 12. Thermogravimetric A naly ses of ADU Reduced in $\mathrm{H}_{2}$ ard Ar-4\% $\mathrm{H}_{2}$. 
TABLE 8. COMPARISON OF UO $\mathrm{UO}_{2}$ POWDERS FROM REDUCING ADU IN $\mathrm{H}_{2}$

AND IN AR - $4 \% \mathrm{H}_{2}$

\begin{tabular}{|c|c|c|c|c|c|}
\hline $\begin{array}{c}\text { Gas } \\
\text { Used for } \\
\text { Reduction }\end{array}$ & $\begin{array}{c}\text { Oxygen/Metal } \\
\text { Atom Ratio }\end{array}$ & $\begin{array}{c}\text { Tap } \\
\text { Density } \\
\left(\mathrm{g} / \mathrm{cm}^{3}\right)\end{array}$ & $\begin{array}{c}\text { BET } \\
\text { Surface } \\
\text { Area } \\
\left(\mathrm{m}^{2} / \mathbf{g}\right)\end{array}$ & $\begin{array}{c}\text { Porosity } \\
\text { (\%) }\end{array}$ & $\begin{array}{c}\text { Fisher } \\
\text { Particle } \\
\text { Size }\end{array}$ \\
\hline $100 \% \mathrm{H}_{2}$ & $\therefore \quad 2.15$ & 1.47 & 10.8 & 0.8 & 1.6 \\
\hline $\mathrm{Ar}-4 \% \mathrm{H}_{2}$ & 2.10 & 1.76 & 3.70 & 0.8 & 1.8 \\
\hline
\end{tabular}

\section{TABLE 9. EFFECT OF FURNACE REDUCTION CYCLE ON SPECIFIC SURF ACE AREA OF $\mathrm{UO}_{2}$}

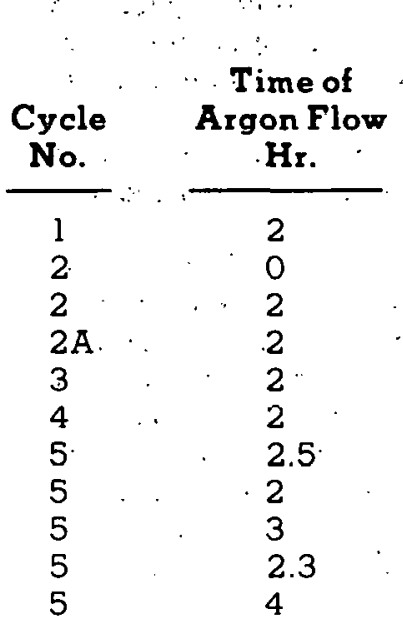

Cycle No.

1

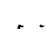

Furnace Temp. when $\mathrm{H}_{2}$ : Admitted, degrees $\mathrm{C}$

215

25

215

215

225

265

525 .

425

625

485

825
Max. Reducing Temp. degrees $C$

700

750

750

850

700

850

850

850

850

850

850
Time at Max.
Reducing

Temp., Hr.

2 .

2 .

2

- 2

2

5.5

5:7

5.7

5.7

5.7

5.7
Average Surface Ârea $\mathrm{m}^{2} / \mathrm{g}$

20.0

20.7

16.6

13.2

15.2

12.7

10.2

10.9

7.46

$11.5^{\star}$

4.0

Furnace Heating Cycle

Room temperature to $200 \mathrm{C}$ at $100 \mathrm{C} / \mathrm{hr}$; 200 to $300 \mathrm{C}$ at $50 \mathrm{C} / \mathrm{hr}$; 300 to $350 \mathrm{C}$ at $100 \mathrm{C} / \mathrm{hr}$;

350 to $400 \mathrm{C}$ at $30 \mathrm{C} / \mathrm{hr}$;

440 to $700 \mathrm{C}$ at $100 \mathrm{C} / \mathrm{hr}$;

Hold at $700 \mathrm{C}$ for $2 \mathrm{hr}$, furnace cool.

2

Same as cycle 1, except upper temperature is $750 \mathrm{C}$.

$2 \mathrm{~A}$

Same as cycle 1, except upper temperature is $850 \mathrm{C}$.

3

Room temperature to $700 \mathrm{C}$ at $100 \mathrm{C} / \mathrm{hr}$;

Hold $2 \mathrm{hr}$; furnace cool.

4

Room temperature to $850 \mathrm{C}$ at $120 \mathrm{C} / \mathrm{hr}$;

Hold 5-1/2 hr; furnace cool.

5 Room temperature to $850 \mathrm{C}$ at $200 \mathrm{C} / \mathrm{hr}$;

Hold $5 \mathrm{hr} 40 \mathrm{~min}$; furnace cool.

-In this test the hydrogen flow rate was increased to 20 system volumes per minute. 
dissipated, raises the temperature of the $\mathrm{UO}_{2}$ to ignition, causing it to burn in the air to $\mathrm{U}_{3} \mathrm{O}_{8}$. Thus $\mathrm{Anderson}$ et al. (Reference 19) observed that freshly reduced $\mathrm{UO}_{2}$ powder with a specific surface area of 8.4 square meters per gram or greater is pyrophoric in ambient air. If the initially evolved heat is rapidly dissipated or if the $\mathrm{UO}_{2}$ powder is comparatively coarse, so that no pyrophoric reaction occurs, continued exposure of the $\mathrm{UO}_{2}$ powder to air after the initial chemisorption of the oxygen monolayer causes a slow, long-time uptake of oxygen. This slow, long-time uptake of additional oxygen by $\mathrm{UO}_{2}$ powder, which has already received an initial monolayer of oxygen, can be controlled by storing the powder out of contact with the air.

Treating a freshly reduced $\mathrm{UO}_{2}$ powder of high specific surface area to prevent it from undergoing excessively rapid oxidation on exposure to air is termed stabilization. Three methods for stabilizing freshly reduced $\mathrm{UO}_{2}$ powder were studied:

a. Moistening the $\mathrm{UO}_{2}$ powder by tumbling it with an amount of water equal to about 1 percent of the weight of the powder: The moisture occupies the adsorption sites on the particles. The adsorption of oxygen is retarded, due to the necessity of displacing the moisture film. Thus the adsorption of the initial oxygen monolayer occurs so slowly that adequate dissipation of the heat of adsorption occurs. Tests showed that 5 grams of water tumbled with 550 grams of freshly reduced $\mathrm{UO}_{2}$ powder, with a specific surface area of 10 to 13 square meters per gram, prevented the powder from igniting when it was exposed to air.

b. Mixing the $\mathrm{UO}_{2}$ powder, even while still hot, with four to five times its volume of powdered dry ice and exposing it to the atmosphere: The $\mathrm{UO}_{2}$ powder is cooled to below room temperature, causing protective moisture from the air to condense throughout it. Also it is blanketed with gaseous carbon dioxide, through which the air must diffuse in order to oxidize the particle surtaces. The initial oxygen monolayer is adsorbed on the $\mathrm{U}_{2}$ particles slowly, with rapid dissipation of the heat of adsorption. In tests of this dry ice method, freshly reduced $\mathrm{UO}_{3}$ powder with a specific surface area as high as 20 square meters per gram was successfully stabilized.

c. Controlling adsorption of an oxygen monolayer from moist ambient air onto thin layers of $\mathrm{UO}_{3}$ powder on a metal cooling plate. following contacting the powder with a moist inert gas: Under a blanket of moist argon, the $\mathrm{UO}_{2}$, powder is vibrated down a 6 -foot-long, transversely corrugated, inclined. aluminum metal cooling plate. Halfway down the plate the powder meets a countercurrent stream of moist air. Displacing the molecules of water vapor already adsorbed on the surface of the $\mathrm{UO}_{2}$ powder, the monolayer of oxygen adsorbs slowly. The heat of adsorption is rapidly transferred from the thin layer of powder to the cooling plate heat sink. This equipment, shown in schematic in the flowsheet of Figure 11, was extremely convenient in use. By means of it, freshly reduced $\mathrm{UO}_{2}$ powder with a specific surface area as great as 13 square meters per gram was successfully stabilized. This stabilization method was chosen for the production process.

\section{B. Urania Conversion Production Process}

From the results of the developmental study, the parameters for the production scale urania conversion process were established (Figure 13 ). The production process employed a commercial furnace permitting zone control of the furnace atmosphere and temperature. To establish the optimum operating conditions for the production furnace, a series of test runs was made at the parametric conditions of the process schematic, except that the hydrogen reduction temperature plateau was varied over the range from 400 to $650 C$. The dependence of the specific surface area of the ${ }^{23.3} \mathrm{UO}_{2}$ powder product upon the hydrogen reduction temperature under production line conditions, as obtained from these test runs, is shown in Figure 14.

On the basis of the data of Figure 14, the hydrogen reduction temperature was set at $650 \mathrm{C}$ in order to meet the ${ }^{2.3 .3} \mathrm{UO}_{2}$ specific surface area requirement of $6_{-2}^{+3}$ square meters per gram. The data of Table 9 show that the temperature at which the ADU is first exposed to the hydrogen atmosphere is crucial in determining the specific surface area of the ${ }^{233} \mathrm{UU}_{2}$ powder. In line with this, the furnace was set to maintain an argon atmosphere in the heat-up zone. Only after the ADU had reached.the zone at the specified reduction temperature was it exposed to the hydrogen atmosphere. The measured furnace temperature profile to which the $\mathrm{ADU}$ was subjected during passage through the furnace for conversion into ${ }^{23.3} \mathrm{UO}_{\mathfrak{J}}$ is shown in $\mathrm{Fig}$ ure 15 . 


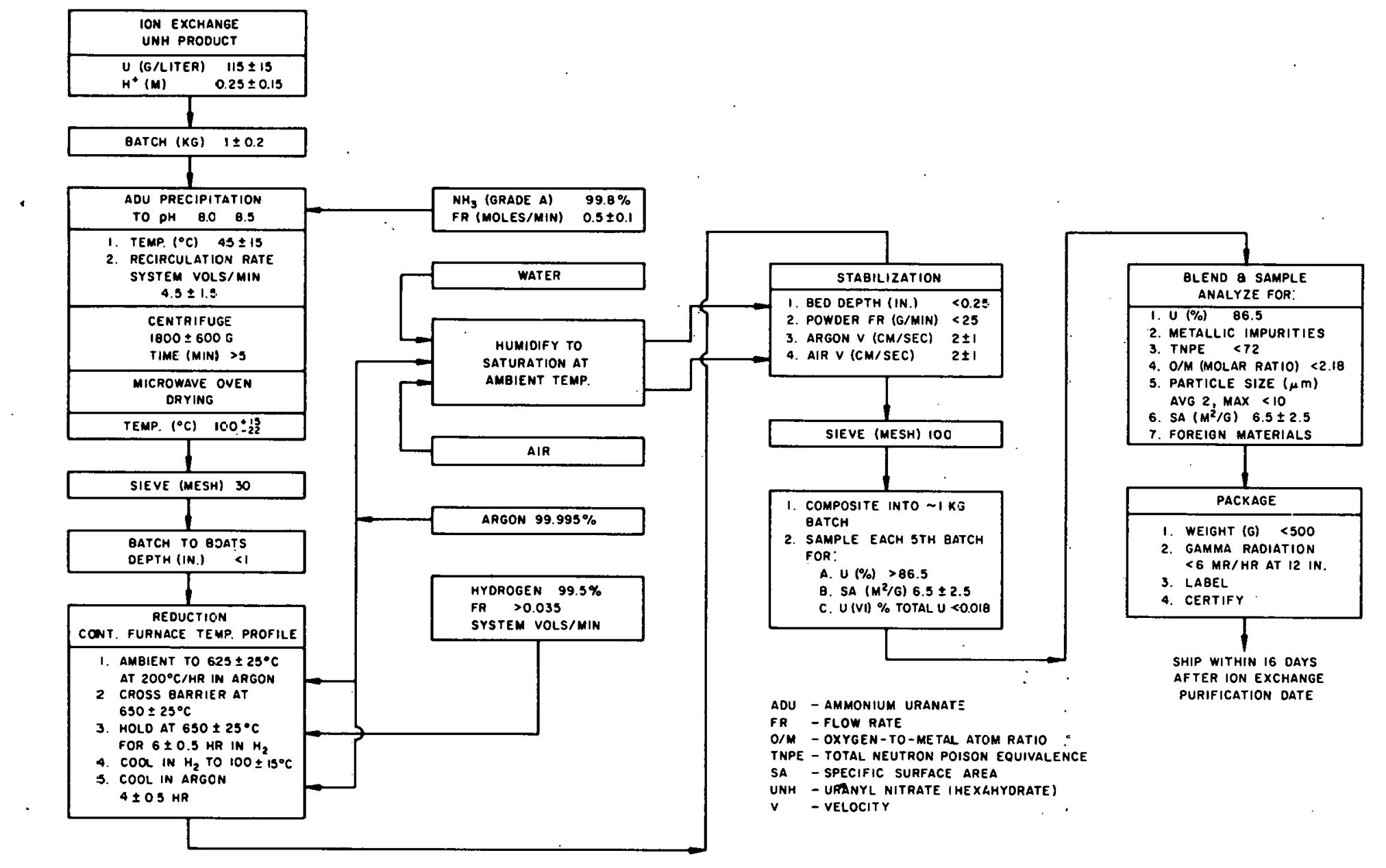




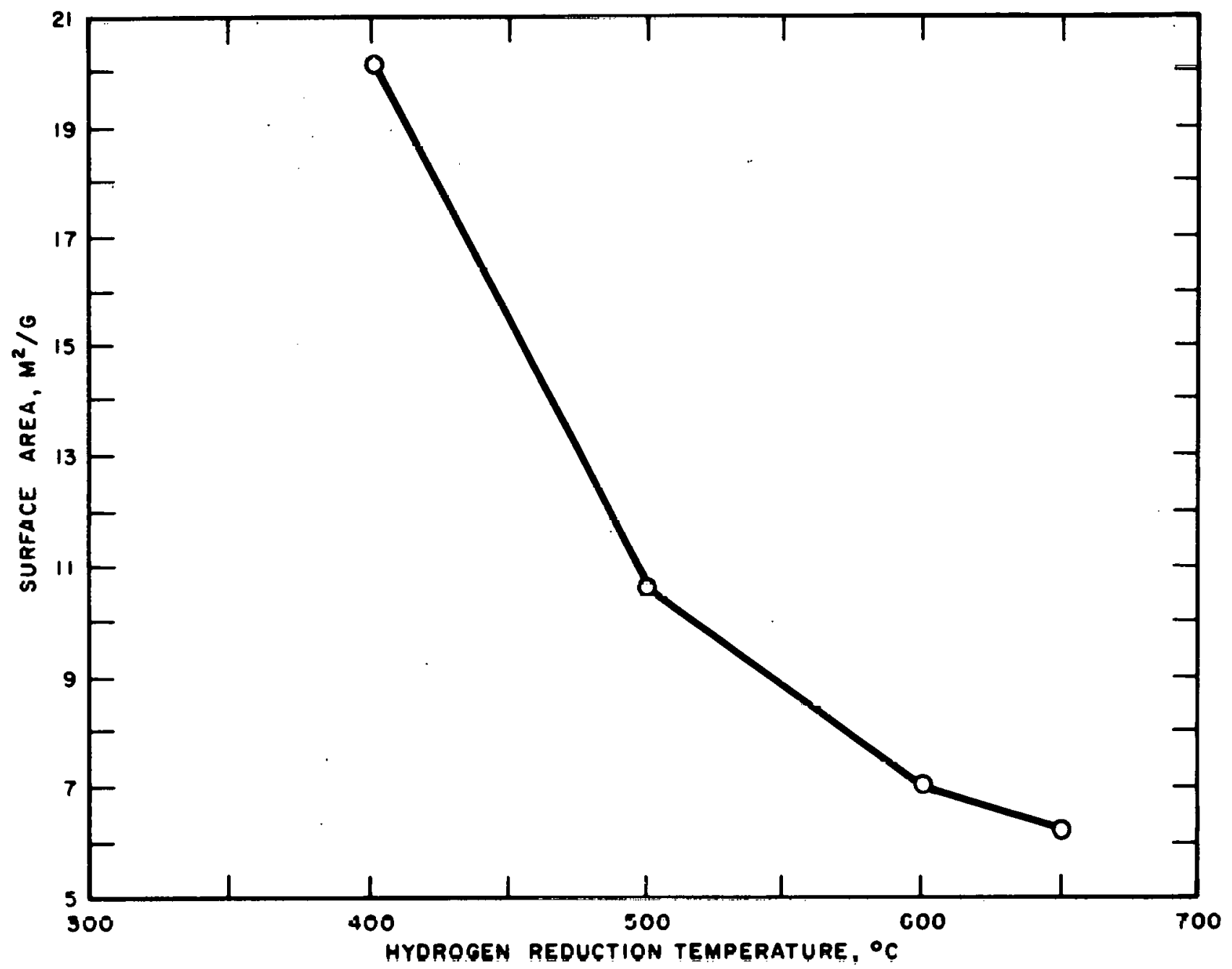

Figure 14. Dependence of Specific Surface Area of ${ }^{233} \mathrm{UO}_{2}$ Powder upon Hydrogen Reduction Temperature under Production Line Conditions. 


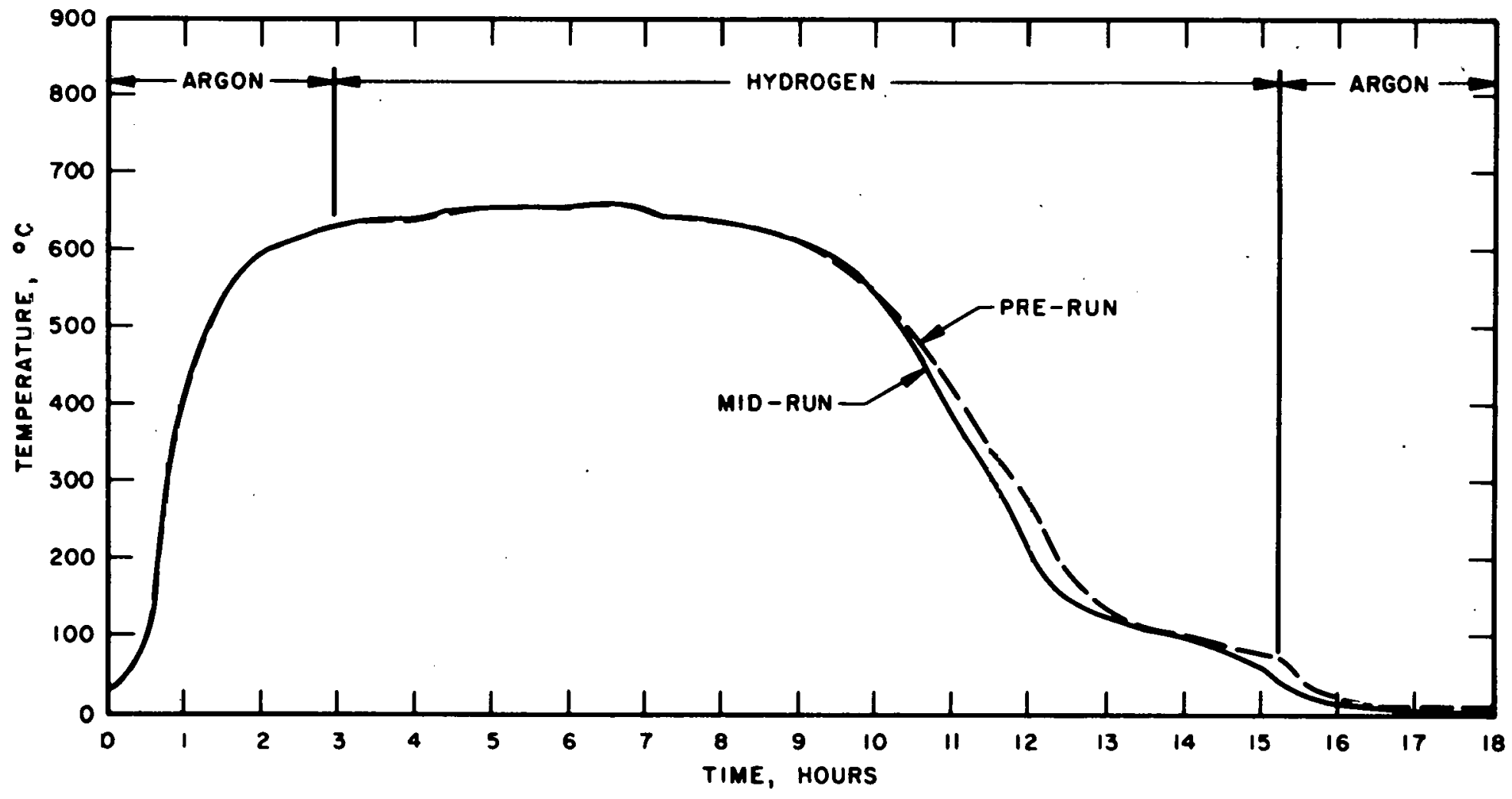


TABLE 10. SUMMARY DATA SHEET FOR $\mathrm{UO}_{2}$ POWDER PRODUCT

(LOT NUMBER 23)

\section{Analyses Performed}

U conc., wt \%

${ }^{232} \mathrm{U}, \mathrm{ppm} \mathrm{U}$

${ }^{233} \mathrm{U}$, wt \%

${ }^{234} \mathrm{U}$, wt $\%$

${ }^{235} \mathrm{U}$, wt $\%$

${ }^{236} \mathrm{U}$, wt $\%$

${ }^{238} \mathrm{U}$, wt $\%$

Impurities, wt ppm $\mathrm{UO}_{2}$

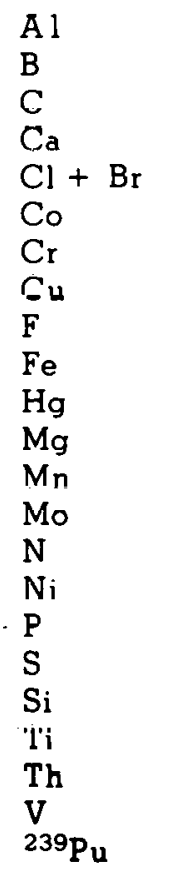

Total neut. poison equiv.

Surface area, $\mathrm{m}^{2} / \mathrm{g}$

$\mathrm{O} / \mathrm{M}$ mole ratio

Mristure, wt ${ }^{2}$

Avg. particle size, $\mu$

ant deter mined.

Excluding $N$

'Not applicable.
Analytical Results

\begin{tabular}{|c|c|}
\hline $\begin{array}{l}\text { Purified } \\
\text { Nitrate } \\
\end{array}$ & $\begin{array}{l}\text { Product } \\
{ }^{233} \mathrm{UO}_{2} \text { Powder } \\
\end{array}$ \\
\hline- & 87.5 \\
\hline 9 & 9 \\
\hline 98.53 & 98.53 \\
\hline 1.228 & 1.231 \\
\hline 0.033 & 0.033 \\
\hline 0.004 & 0.004 \\
\hline 0.199 & 0.200 \\
\hline
\end{tabular}

200

3

500

50

25

15

100

40

30

400

30

100

20

100

50

200

150

15

200

20

500

50

25

$<72$

$\begin{aligned} & 6+3 \\ < & 2.18 \\ < & 0.5 \\ < & 2\end{aligned}$

\begin{tabular}{c}
$\begin{array}{c}\text { Raw } \\
\text { Nitrate }\end{array}$ \\
\hline- \\
9 \\
98.54 \\
1.225 \\
0.024 \\
0.001 \\
0.199
\end{tabular}

7

0.8

a

46

86

$<1$

4

12

4

55

18

$<2$

$<2$

$<4$

46

33

$<13$

$<53$

7

$<4$

$<18$

c

\section{c}

c

ᄃ

c$$
4.65
$$

a

7

$<5$

$<1$

18

14

$<5$

30

6

4
5

$<2$

a

6
38

24

35.

$\checkmark 1$

6

$<1$

$37.16^{b}$

c

c

s.

c
7

0.5

35

11

11

0.3

4

12

$<5$

30

$<1$

1

$<0.5$

16

10

40

10

55

$<.1$

4
$<1$

2

39.08

6.55

2.05

0.23

0.5 
1. Urania Conversion Production Process Evaluation. The urania conversion production process and equipment were evaluated by a series of preproduction runs in which a total of 26 lots of ${ }^{233} \mathrm{UO}_{2}$ powder were prepared. The lots ranged in size from a single l-kilogram batch to six l-kilogram batches. Some of the ${ }^{233} \mathrm{UO}_{2}$ powder product was sent to Bettis for their preproduction studies, but most of it, after characterization, was dissolved in nitric acid for recovery and storage of its uranium-233 content.

The characterization data obtained from the powder lots included the impurity analysis of the uranium233 storage tank solution before and after the ion exchange decontamination and purification operations, and also the impurity analysis of the ${ }^{233} \mathrm{UO}_{2}$ powder product. The pertinent physical attributes of the powder were also determined. These included the specific surface area of the powder and its average particle diameter. The characterization data from ORNL preproduction lot number 23, consisting of five l-kilogram batches of ${ }^{233} \mathrm{UO}_{2}$, are presented in Table 10 as typical of the results from the preproduction runs. Figure 16 gives radiation field data measured on ORNL preproduction lot number 21 , which consisted of six 1 kilogram batches of ${ }^{233} \mathrm{UO}_{2}$. These data are typical of the rate of the radioactivity regrowth in a 500 gram portion of the ${ }^{233} \mathrm{UO}_{2}$ powder product. Extrapolation of the radiation field data plot shows that up to approximately four weeks after the ion exchange decontamination of the uranium-233, the ${ }^{233} \mathrm{UO}_{2}$ product made from it has a radiation field that is less than the specified 6 mrem per hour at 1 foot.

The 26 preproduction runs were an evaluation of the ion exchange decontamination and purification production process, the urania conversion production process, and the production process equipment. They also served as an evaluation of the training of the operating personnel. The results of these runs demonstrated that the process operating parameters yielded a ${ }^{233} \mathrm{UO}_{2}$ product which met all of the Bettis specifications.

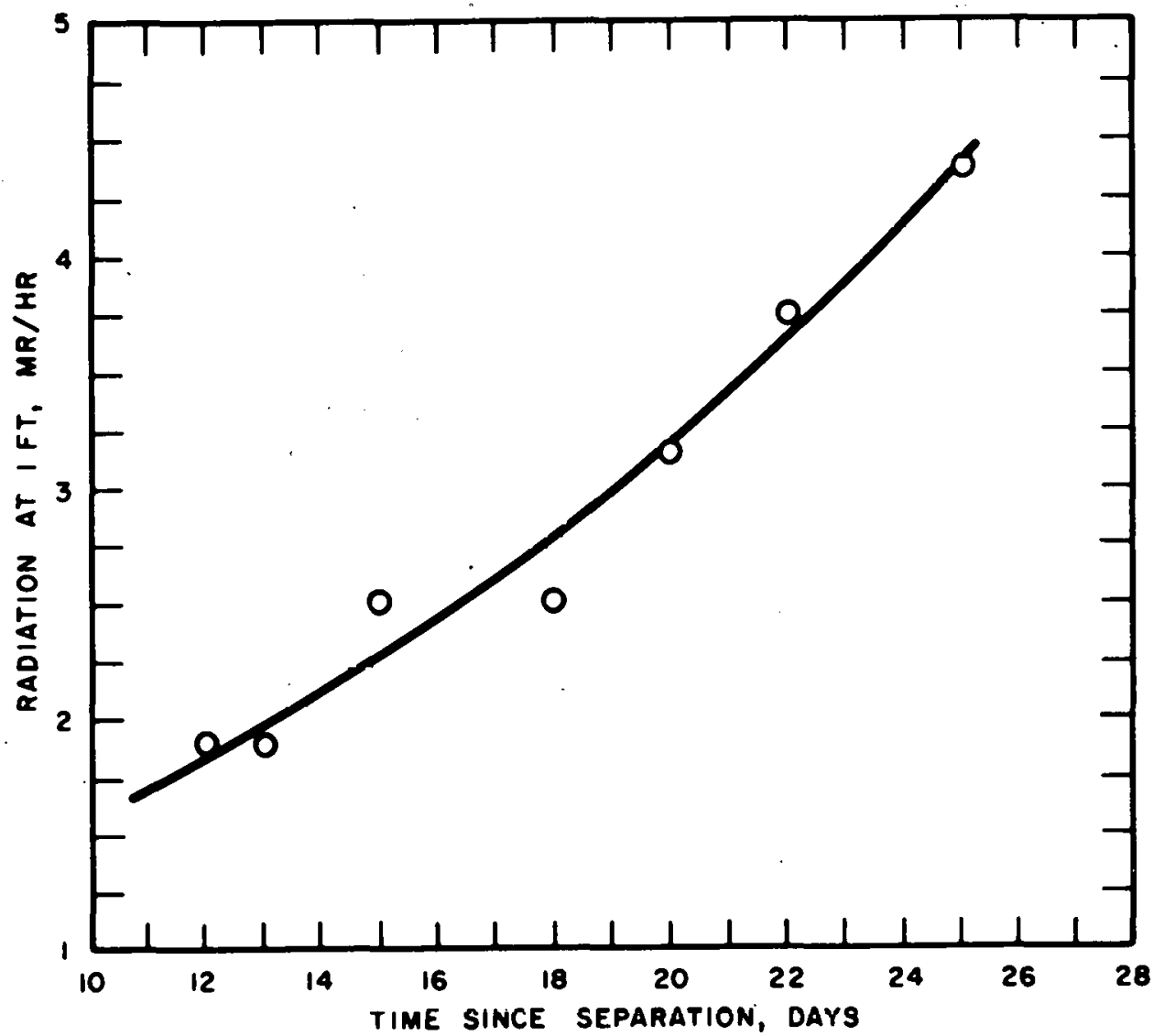

Figure 16. Radiation as a Function of Time Since Separation for $500 \mathrm{~g}$ of ${ }^{233} \mathrm{UO}_{2}$ Powder (Containing 6.25 ppm of ${ }^{232} U$ ) from Lot Number 21 . 


\section{URANIUM-233 PURIFICATION AND ${ }^{23} \mathrm{UO}_{2}$ CONVERSION PROCESS OUTLINE}

Based upon the experimental process development studies and the production process evaluations, the outline of the parameters of the combined ion exchange decontamination and purification of the uranium233 and of its conversion into ${ }^{233} \mathrm{UO}_{2}$ is presented in Table 11 . This process outline also includes the parameters of the solvent extraction operations involved in the recovery of uranium-233 from the ion exchange column eluate and from the solution of the binary fuel scrap and grinding swarf. Operating in accordance with this process outline, ORNL produced on schedule with no signficant problems the ${ }^{233} \mathrm{UO}_{2}$ powder used in fabricating the LWBR core.

\section{TABLE 11 . PROCESS OUTLINE FOR DECONTAMINATION AND PURIFICATION OF URANIUM-233 AND FOR ITS CONVERSION TO URANIA}

\section{Process Step}

1. Purification of uranyl nitrate

A. Solvent extraction (for recovery of ${ }^{203} \mathrm{U}$ from ion exchange column eluate and from solution of $\mathrm{ThO}_{2}$ ${ }^{233} \mathrm{UO}_{2}$ scrap and grinding swarf)

B. Ion exchange

2. Precipitation preparation

3. Procipitation of ADI
Process Parameters

a. Extraction column feed: $3.10 \mathrm{~g} / 1 \mathrm{U}, 120-200 \mathrm{~g} / 1 \mathrm{Th}$, 1.7-2.0 $\mathrm{M} \mathrm{HNO}_{3}$

b. Extractant: $5 \%$ di-sec-butyl-phenylphosphonate in diethyl-benzene

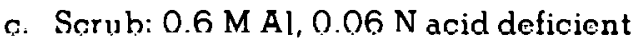

d. Strip: $0.01 \mathrm{M} \mathrm{HNO}_{3}$

e. Product (after concentration in an evaporator): $250 \mathrm{~g} / \mathrm{l} \mathrm{U}$ for storage or $120 \pm 10 \mathrm{~g} / \mathrm{l} \mathrm{U}$ for ion exchange feed; U/Th weight ratio greater than 1000

a. Resin: Bio Rad AG-W50 X12, 200100 mooh

b. Ion exchange column feed: $120 \pm 10 \mathrm{~g} / 1 \mathrm{U}$, less than $0.4 \mathrm{MHNO}_{3}$, ambient temperature,

c. Flow rate: $100 \pm 10 \mathrm{ml} / \mathrm{min}$ at a pressure not greater than $150 \mathrm{lb} / \mathrm{in}^{2}$.

d. Eluent: $6 \mathrm{M} \mathrm{HNO}_{3}$ at $60 \mathrm{C}$

a. Uranium concentration: $115 \pm 15 \mathrm{~g} / 1$

b. $\mathrm{HNO}_{3}$ free acid concentration: 0.1 to $0.4 \mathrm{~N}$

c. Solution temperature: $35 \pm 15 \mathrm{C}$

a. Batç £izo: $1000 \pm 200$ g uranium

b. $\mathrm{NH}_{3}$ flow rate: $0.395 \pm 0.079 \mathrm{ft}^{3} / \mathrm{min}$

c. Solution temperature: $40 \pm 20 \mathrm{C}$

d. Recirculation rate of solution: $45 \pm 15 \mathrm{l} / \mathrm{min}$ 
TABLE 11 (Cont)

Process Step

4. Recovery of $A D U$ by centrifuge

5. Drying ADU in microwave oven

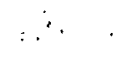

6. Sieving ADU

7. Reduction of $A D U$ to uranium dioxide

8. Stabilization of uranium dioxide powder by controlled exposure to air

\section{Process Parameters}

e. Precipitation completed when $\mathrm{pH}$ of 8.25 is reached

f. Precipitate transferred to centrifuge within 30 minutes after precipitation is completed.

a. Batch size: $1000 \pm 200 \mathrm{~g}$ uranium

b. Centrifuge force: $1800 \pm 600 \mathrm{~g}$

c. Time: Minimum of 5 minutes to maximum of 60 minutes after addition of precipitate to centrifuge

d. ADU cake washed with $8 \pm 2$ l of demineralized water

e. Atmosphere: Air at ambient temperature

a. Batch size: $1000 \pm 200 \mathrm{~g}$ uranium

b. Microwave drying cycle: $100 \pm 15 \mathrm{C}$

(1) Forward power level: $2 \mathrm{kw} \pm 0.20 \mathrm{kw}$ for $1 \mathrm{hr}$ $\pm 45 \mathrm{~min}$

(2) Forward power level: $1 \mathrm{kw} \pm 0.20 \mathrm{kw}$ for $1 \mathrm{hr}$ $\pm 45 \mathrm{~min}$

c. Atmosphere: Air

a. 30 mesh sieve

b. Atmosphere: Air at ambient temperature

a. Reduction is performed in continuous multizoned furnace with an Incoloy and stainless steel muffle using Inconel furnace hardware

b. Depth of ADU not to exceed 1 in.

c. Reduction cycle:

(1) Heated from ambient to $625 \pm 25 \mathrm{C}$ in $3 \pm 0.5 \mathrm{hr}$ in $\mathrm{Ar}$

(2) Gas barrier transition ( $\mathrm{Ar}$ to $\mathrm{H}_{2}$ ) at $650 \pm 25 \mathrm{C}$

(3) Held at $650 \pm 25 \mathrm{C}$ for $6 \pm 0.5 \mathrm{hr}$ in $\mathrm{H}_{2}$

(4) $\mathrm{H}_{2}$ flow rate a minimum of $0.074 \mathrm{ft}^{3} \mathrm{~min}$

a. Temperature: Ambient

b. Bed depth: <1/4 inch

c. Powder flow rate: Average rate $-25 \mathrm{~g} / \mathrm{min}$ minimum 
TABLE 11 (Cont)

Process Step

9. Sieving uranium dioxide

10. Powder blending to produce homogenous powder lot not exceeding $30 \mathrm{~kg}$ uranium

11. Packaging

12. Shipping

\section{Process Parameters}

d. Argon flow rate: $0.125 \pm 0.067 \mathrm{ft}^{3} / \mathrm{min}$

e. Air flow rate: $0.125 \pm 0.067 \mathrm{ft}^{3} / \mathrm{min}$

f. Both Ar and air are bubbled through demineralized water at ambient temperature

a. 100-mesh sieve

b. Atmosphere: Air at a mbient temperature

a. Type blender: V-blender

b. Blending time: $1 \pm 0.5 \mathrm{hr}$

c. Blender speed: $25 \pm 2 \mathrm{rpm}$

d. Samples are drawn from each blended powder lot for analysis and certification to order specification requirements

a. Samples are packaged a maximum of $500 \mathrm{~g}$ of ${ }^{233} \mathrm{U}$ in screw top stainless steel container.

b. Screw top container is sealed in isotope container

c. Nu more than two isotope containers are placed in approved shipping vessel.

a. Powder is shipped in accordance with DOT rogulations. 


\section{ACKNOWLEDGMENT}

This report is based upon work done at SRP and HW in producing the uranium-233 and work done at ORNL in developing and carrying out the conversion process for transforming the uranium-233 into urania for use in manufacturing the LWBR fuel. A series of progress reports prepared under the direction of J. R. Parrott of ORNL for submission to Bettis, and also individual reviews prepared by R. H. Rainey and J. M. Leitnaker et al.,. also of ORNL, to document studies carried out by them provided the main sources of data for the report. I acknowledge indebtedness to all these sources upon whose data I have drawn in preparing this report.

\section{REFERENCES}

1. D. R. Connors, J. A. Fest, S. Milani, and R. Atherton, "Design of the Shippingport Light Water Breeder Reactor," WAPD-TM-1208, Bettis Atomic Power Laboratory, West Mifflin, Pennsylvania, January 1979 .

2. J. L. Liverman, "Environmental Assessment of a Conceptual Thorium-Uranium Fuel Cycle," U. S. Energy Research and Development Administration, Light Water Breeder Program, June 1976. ERDA1541 .

3. G. T. Seaborg, and L. I. Katzin, "Production and Separation of Uranium-233," NNES IV-17A (1951).

4. J. M. Boswell, R. D. McCrosky, J. T. Stringer, and W. K. Woods, "Production of ${ }^{2.33} \mathrm{U}$ with Low ${ }^{2.32} \mathrm{U}$ Content," Proceedings of Second International Thorium Fuel Cycle Symposium, May 3-6, 1966. Edited by R. G. Wymer, CONF-660524, pp 745-763, February 1968.

5. O. A. Towler, Jr., "Thorium Irradiation in $\mathrm{D}_{2} \mathrm{O}$-Moderated Reactors," Proceedings of the First International Thorium Fuel Cycle Symposium, USAEC Report TID-7.550, Book II, ORNL, December 5-6, 1962.

6. J. L. Crandall, J. A. Smith, and O. A. Towler, "A Description of the Savannah River High Flux Charge, in the Savannah River High Flux Demonstrations," USAEC Report DP-999, SRL, June 1965.

7. R. H. Meichle, "Clean Uranium-233 Production Methods and Parameters," Trans. Am. Nucl. Soc. 8 (2), 520 (1965).

8. R. H. Rainey, and J. G. Moore, "Laboratory Development of the Acid Thorex Process for Recovery of Thorium Reactor Fuel," Nucl. Sci. Eng. 10, 367-371 (1961).

9. H. C. Rathvon, A. G. Blasewitz, R: Maher, J. C. Eargle, Jr., and A. E. Wible, "Recovery of ${ }^{23.3} \mathrm{U}$ from Irradiated Thoria," Proceedings of Second International Thorium Fuel Cycle Symposium, May 3-6. 1966, Edited by R. G. Wymer, C.ONF-660524, pp 765-824, February 1968.

10. R. H. Rainey, "Laboratory Development of a Pressurized Cation Exchange Process for Removing the Daughters of ${ }^{232} \mathrm{U}$ from ${ }^{233} \mathrm{U}, "$ ORNL-4731 (December 1972).

11. R. E. Brooksbank, J. P. Nichols, and A. L. Lotts, "The Impact of Kilorod Facility Operational Experience on the Design of Fabricating Plants for ${ }^{233} \mathrm{U}$-Th Fuels," Proceedings of Second International Thorium Fuel Cycle Symposium, May 3-6, 1966, Edited by R. G. Wymer, CONF-660524, pp 321-334, February 1968.

12. J. Belle, Editor, "Uranium Dioxide: Properties and Nuclear Applications," Naval Reactors, Division of Reactor Development, USAEC, U. S. Govt. Printing Office, Waohington, D.C., 1981.

13. J. L. Woolfrey, "The Preparation and Calcination of Ammonium Uranates - A Literature Survey," AAEC/TM-476 (Seplember 1968). 
14. J. M. Leitnaker, M. L. Smith, and C. J. Fitzpatrick, "Conversion of Uranium Nitrate to Ceramic Grade Oxide for Light Water Breeder Reactor: Process Development," ORNL-4755 (April 1972).

15. E. H. P. Cordfunke, "On the Uranates of Ammonium-I. The Ternary System $\mathrm{NH}_{3}-\mathrm{UO}_{3}-\mathrm{H}_{2} \mathrm{O}, "$ J. Inorg. Nucl. Chem. 24, 303-307 (1962).

16. W. I. Stuart and T. L. Whately, "Composition and Stucture of Ammonium Uranates," J. Inorg. Nucl. Chem. 31, 1639-1647 (1969).

17. S. Brunauer, P. H. Emmet, and E. Teller, "Adsorptior óf Gáses in Multimolecular Layers," J. Am. Chem. Soc. 60. 309-319 (1938).

18. ASTM Method B 330-76, "Standard Test Method for Average Particle Size of Powder of Refractory Metal and Compounds, by Fisher Sub-sieve Sizer," Annual Book of ASTM Standards, Part 9, Am. Soc. for Testing and Materials, Philadelphia, Pa., 1978.

19: J. S. Anderson, L. E. J. Roberts, and E. A. Harper, "The Oxides of Uranium, Part VII: The Oxidation of Uranium Diọide," J.Chem. Śc., 3946-3959, (1955). 


\section{APPENDIX}

\section{URANIUM-232 AND ITS DAUGHTER PRODUCTS}

The uranium-233 produced in the thorium fuel cycle contains 74 y uranium-232, formed mainly as the result of a $6.37 \mathrm{Mev}$ threshold $(n, 2 n)$ reaction in the irradiation of the thorium. The alpha-decay of this relatively short half-life uranium isotope yields daughter products, starting with radiothorium (thorium228), that include $3.1 \mathrm{~m}$ thallium-208 which, in undergoing beta-decay, emits a hard gamma photon of $2.6 \mathrm{Mev}$ energy. The formation and decay of the uranium-232 are described by the sequence of nuclear reactions given in Table A- 1 .

The high energy gamma-radiation field associated with the uranium-232 isotopic contaminant necessitates remote handling of the uranium-233 fuel. However, this field can be temporarily attenuated by chemical reprocessing to remove the thorium -228 and its various daughter products shown in Table A-1. Nevertheless, continued decay of the uranium-232 isotopic contaminant, not removable by chemical reprocessing, rebuilds the gamma-radiation field, which grows to an equilibrium value over a ten-year period. Under conditions of equilibrium with its decay products, 1 milligram of uranium-232 has a gamma-radiation field of approximately 100 mrem per hour at a distance of 1 foot.

Short-time irradiation of thorium at a completely thermalized neutron spectrum yields a very low concentration $(5-10 \mathrm{ppm})$ of the uranium-232 contaminant in the uranium-233 product. In this event, removal of the uranium-232 alpha-decay daughter products reduces the gamma-radiation field enough to allow the uranium-233 to be handled semiremotely (in glove boxes without special gamma-shielding) for an interval of several weeks, pending the rebuildup of the uranium-232 decay products.

The LWBR core at Shippingport was fabricated from uranium-233 with a low concentration of uranium232 contaminant (less than $10 \mathrm{ppm}$ ), so that the gamma radiation field was low enough to allow the fuel to be handled semiremotely. As discussed in Reference 1, operation of prebreeders initially fueled with uranium-235 or other fissile material and with thorium would be used to produce uranium-233. It is likely that the uranium -233 recovered from prebreeders or breeders would have higher concentrations of uranium232 than the uranium-233 used for the Shippingport LWBR core. At this higher level of uranium-232 contamination, the rate and extent of rebuildup of the gamma radiation field in the uranium-233 fuel are such that chemical reprocessing to remove thorium-228 and its daughters will not eliminate the need for remote handling in a heavily gamma-shielded facility. 
is

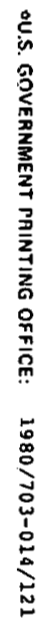

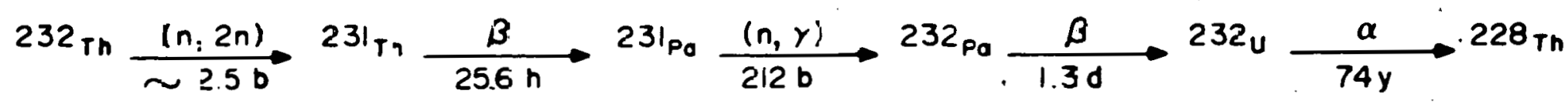

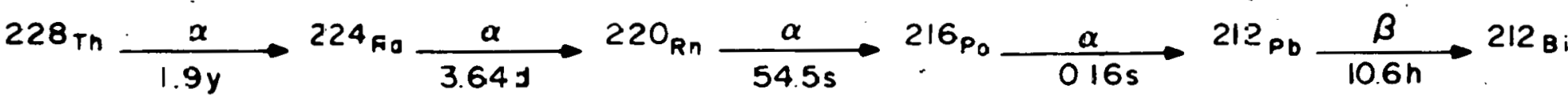

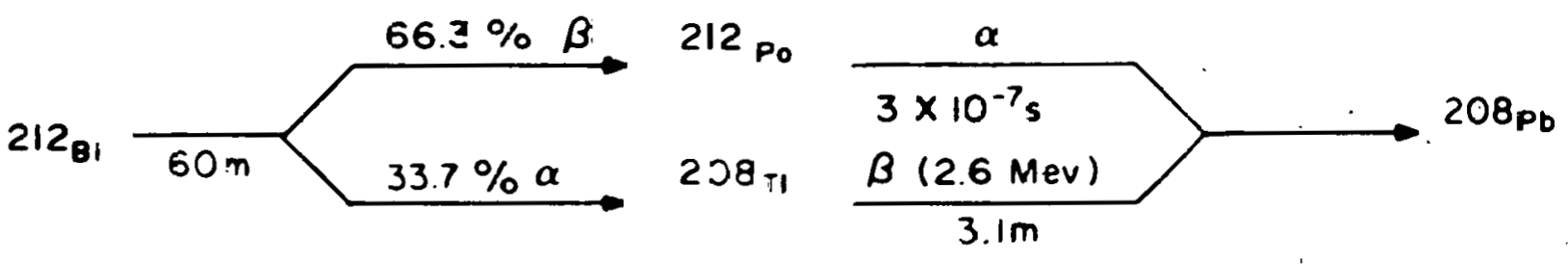

TABLE A-1. NUCLEAR REACTIONS IN THE FORMATION

AND DECAY OF URANIUM -232 